Maximilian Ueberschaar, Daniel Dariusch Jalalpoor, Nathalie Korf, Vera Susanne Rotter

\title{
Potentials and Barriers for Tantalum \\ Recovery from Waste Electric and Electronic Equipment
}

\section{Article, Postprint}

This version is available at https://doi.org/10.14279/depositonce-6369.

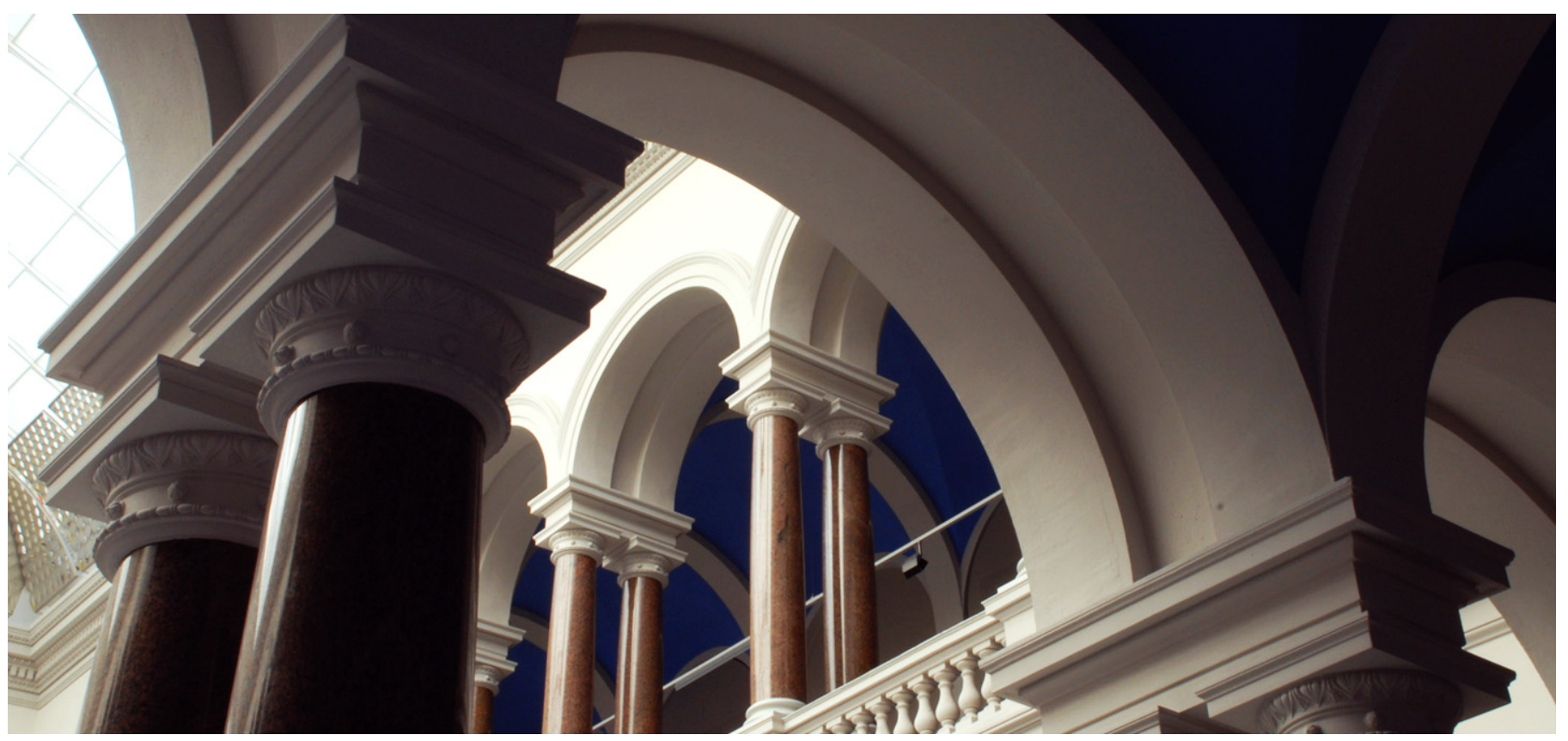

\section{Suggested Citation}

Ueberschaar, Maximilian; Jalalpoor, Daniel Dariusch; Korf, Nathalie; Rotter, Vera Susanne: Potentials and Barriers for Tantalum Recovery from Waste Electric and Electronic Equipment. - In: Journal of industrial ecology. - ISSN: 1530-9290. - 21 (2017), 3. - pp. 700-714. (Postprint version is cited, page numbers may differ.) 


\section{Abstract}

Circular economy approaches aim to close material cycles along the value chain. As such it can be a long-term strategy to mitigate the risks of critical raw material (CRM) supply. Tantalum, with a current end-of-life recycling rate of less than $1 \%$, has been intermittently discussed as critical. Even though the specificity of tantalum applications and high mass fractions of tantalum in relevant components provide good boundary conditions, recycling barriers hinder the successful implementation of recycling technologies. With this case study, we identify potentials and barriers for implementing the recovery of CRM, using the example of tantalum.

To this end, information about visually identifiable tantalum capacitors (VICS) and printed circuit boards (PCBs) in various equipment types was obtained via disassembly campaigns for mobile phones, smartphones, tablets, notebooks, desktop PCs, flat screen monitors, servers, etc. and the chemical analyses of resulting fractions.

Results show great differences in the application of tantalum in various equipment types. Due to this, the tantalum potential of put-on-market (POM) or of Waste Electric and Electronic Equipment (WEEE) devices differs between products and regions. Worldwide, the highest POM tantalum flows originate from desktop computers, but in Germany they originate from notebooks. A focus on particular products leads to higher yields in recycling and supports circular economy approaches.

Recycling of tantalum from WEEE is generally possible. But an accurate separation of tantalum from PCBs is not feasible solely by separation of VICs. This process also leads to the loss of silver. Furthermore, this study reveals potential miniaturization trends, decreasing the use of VICs, with an anticipated substitution of tantalum with niobium. These barriers impede long-term recycling strategies for tantalum aimed at establishing a circular economy. 


\section{Introduction}

Economical and technical recycling barriers are key factors affecting the criticality of commodities in our economic system (European Commission 2010, 2014; Hatayama and Tahara 2014; Graedel and Reck 2016). In this context, circular economy can be seen as a strategy and policy to reduce related risks.

In 2010, in a report on Critical Materials for the EU, the European Commission defined tantalum as one of 14 critical elements, both in terms of economic importance and security of supply. Tantalum was listed due to the fact that it is primarily produced in politically unstable areas (European Commission 2010). In a revision of this report tantalum was removed from the list as no longer to be considered a highly critical material (European Commission 2014), though other studies still consider it to be so (Hatayama and Tahara 2014). In either case, tantalum has high economic importance due to its use in almost every complex electronic product in the information and communications sector in the form of tantalum capacitors (Chancerel et al. 2013; Cunningham 2001), resistors, or thin film $\mathrm{Ta}(\mathrm{Si}) \mathrm{N}$ barrier layers for preventing interaction in integrated circuits (ICs) (Fitzpatrick et al. 2015). Rising sales of these products, such as mobile phones, tablets, and notebooks, lead to a higher demand for tantalum.

Although such tantalum-containing Waste Electric and Electronic Equipment (WEEE) devices are collected for recycling purposes, a circular economy has not been established for this material. Recycling rates for tantalum are very low, at less than 1\% (UNEP 2013). State of the art recycling processes for printed circuit boards (PCBs) are based on pyrometallurgical approaches that focus on the recovery of copper and precious metals (Chancerel et al. 2009, 2010). Integrated processes allow the recovery of additional elements such as $\mathrm{Pb}, \mathrm{As}, \mathrm{In}, \mathrm{Te}$, etc. However, tantalum ends up in the slag, where it is oxidized. Due to low tantalum grades in the slag, recovery is hindered by high energy demands and high costs (UNEP 2013). Recycling options have been established only for new tantalum capacitor scrap and concentrated slags (H.C. Starck 2011), with recycling rates claimed to 
be approximately $20-30 \%$ (Schwela 2010). In order to move towards long-term sustainability of tantalum, end-of-life recycling should also be improved. The relatively high concentration of tantalum in end-uses such as electric and electronic equipment (EEE) could help incentivize increased recycling. Nevertheless, to enable a circular economy of tantalum from WEEE, existing recycling infrastructure needs to be adapted. The generation of tantalum concentrates prior to the smelter process allows them to be fed into existing recycling processes for the production of tantalum scrap and prevents tantalum from being lost. The diversely applied Ta-capacitors with a tantalum grade of 40\% - 50\% are potentially recoverable after a manual or mechanical separation (H.C. Starck 2011). Therefore, liberation and recovery options for tantalum capacitors on PCBs need to be investigated in order to reveal recycling strategies and to match future prospects to close material loops.

With this article, we

a) provide fundamental information to enable recovery strategies for tantalum from end-of-life capacitors,

b) assess the technical feasibility of the separation processes for relevant products, and

c) identify recycling barriers related to expected tantalum flows in various product categories.

The article comprises a systematic approach to identify losses and develop strategies to close material cycles for critical raw materials (CRMs). Lessons learned from this case study may enhance the recycling of other elements with low recycling rates as well support circular economy strategies.

\section{Background}

Tantalum is a transition metal with properties very similar to niobium. It is resistant to corrosion by acids at ambient temperatures due to the thin film of tantalum oxide that coats the metal. Tantalum is used broadly for components in the electronics sector, in chemicals (for example, as an anticorrosive agent or as an additive in optical lenses), as a carbide in cutting tools and in various metal alloys. About half of the tantalum consumed each year is used in the electronics sector. Here, major applications are powders and wires for tantalum capacitors. (Wickens 2004; Schwela 2010) 


\section{Tantalum capacitors}

Tantalum capacitors consist of a fireproof and mostly inert epoxy resin cover containing $\mathrm{SiO}_{2}$ and a tantalum rich anode. This anode is based on sintered tantalum with tantalum oxide covering the surface and is connected with a tantalum wire to the cathode material through silver connectors (see illustrations in supporting information section S1 and section S2). The porous structure of the sintered tantalum anode is impregnated with an $\mathrm{MnO}_{2}$ electrolyte and surrounded by a graphite layer. In addition to ca. $48 \%$ - 49\% tantalum, the capacitors contain carbon, silicon, manganese, and silver in large quantities. (Rotter et al. 2013; Spitczok von Brisinski et al. 2014)

\section{Global tantalum flows}

In the following, data collected by the T.I.C. (Tantalum-Niobium International Study Center) between 2002 and 2012 has been summarized (supporting information - section S3). T.I.C represents the major share of actors in the tantalum supply chain, including mining companies, trading, processing, manufacturing, and recycling. For tantalum shipments in particular, the study center claims a very high coverage of the market. The data shows increasing tantalum flows up until 2008 and a doubling of the flows over this time span, from 1,400 Mg per year to almost 3,000 Mg per year. From 2009 on a drop is noticeable, possibly related to the economic crisis. After a short recovery in 2010 and 2011, the amount of total tantalum shipments dropped again to 2,000 $\mathrm{Mg}$ per year, most likely because of sharp increases in the price of tantalum. (Schwela 2010; Buckingham et al. 2014; Tantalum-Niobium International Study Center 2013a, 2013b, 2011)

In general, the flows of tantalum powder and tantalum wires for tantalum capacitors have the highest share of all shipments in the years between 2002 and 2012 . The proportion has dropped from about $45 \%$ before 2006 to under 30\% from 2011 on. The total amount of shipments related to capacitors peaked in the years 2004 to 2008 , to about 1,000 Mg per year, before decreasing back to the 2002 level of about $600 \mathrm{Mg}$ per year. 
A general trend towards miniaturization and the use of less tantalum per capacitor can be observed from the sales data of tantalum grade powder and tantalum wires, as the ratio of tantalum powder per tantalum wire decreases. Only one wire is used per capacitor unit. This may hamper the implementation of a recycling process for tantalum from waste capacitors.

Beyond this discussion of primary tantalum, the recycling potential of WEEE devices has to be considered. The legitimacy of circular economy approaches is based on economically feasible recycling processes and the contribution of secondary raw materials to the production of new goods. This demands sufficient end-of-life tantalum masses which are available for recycling purposes. Chancerel et al., 2015 estimate the metal potential and distribution for relevant products put-onmarket (POM) in Germany for two reference years. For the year 2007 25 \pm 9 Mg and for the year 2012 $22 \pm 11 \mathrm{Mg}$ tantalum were calculated for various WEEE products.

\section{State-of-the-art recycling}

Circular economy approaches are usually limited due to low WEEE collection rates or missing recovery technologies. Recycling represents a process chain, involving various processes and actors. Recycling of tantalum from WEEE is not practiced yet, but first approaches were investigated and tested. The overall recycling procedure for tantalum capacitors consists of three main steps after the collection and liberation of the PCBs: Firstly, the identification, liberation and separation of the tantalum capacitors. Secondly, mechanical processing to remove contaminants like polymers, etc. Third and final step: metallurgical processing in order to generate a tantalum concentrate. This material may be subsequently processed so that it can be used as a secondary raw material in new products (Cymorek 2015; Stenzel 2016).

\section{Identification, liberation and separation of tantalum capacitors}

The liberation and separation of tantalum capacitors is usually done by manually removing the visibly identifiable components. This requires significant labor input and is currently carried out only by 
cross-funded sheltered workshops for test purposes (Rotter et al. 2016b), since high labor costs make this approach non-cost-effective.

Various approaches for mechanical processing have been developed with a view to automating the process. Some of these approaches involve crushing the PCBs and the separation of the capacitors through sieving and classification by mass and magnetism (Oki 2013; Kwon et al. 2016). Other approaches involve liberation via underwater explosion, and these show promising results (Fujita et al. 2014). The tantalum capacitors are then sorted with an eddy-current and a gravity separator. Hayashi and Oki, 2014 have investigated the separation of the different compounds after their detachment from the PCBs and have invented a pneumatic technique that enables high separation efficiencies for tantalum capacitors.

Even robotic approaches are being tested at some research institutions, for some of the more common standardized PCBs (Kreibe and Förster 2016).

\section{Recycling and tantalum recovery from WEEE capacitor scrap}

Most established recycling processes for tantalum capacitors apply acid leaching to separate tantalum from all other parts like electrolyte or coating material. Specifically, the $\mathrm{MnO}_{2}$ content is transferred into water-soluble $\mathrm{MnCl}_{2}$ using an $\mathrm{HCl}$ treatment (Wang et al. 2009; Smokovich 2009). The silver content is thereby recovered from the waste slag.

Mineta and Okabe, 2005 have developed a recycling process by adapting the processes of primary production. Here, total oxidation of the capacitor scrap is followed by a magnetic separation of iron and nickel containing materials. After the addition of water, the process involves two sieving steps and a pulverizing process. Leaching agent $\mathrm{HNO}_{3}$ is then used to remove all compounds except tantalum and tantalum oxides. A second approach was developed recently by Spitczok von Brisinski et al., 2014. In this process, an ionic liquid composed of di-alkyl imidazolium halides and $\mathrm{AlCl}_{3}$ is used to dissolve all components of the capacitor except the tantalum anode. Unfortunately, this approach 
is only applicable to through-hole capacitors, because surface-mounted device capacitors show no reaction.

Fujita et al., 2014 suggest a direct and easy treatment of the tantalum capacitors with heat and a subsequent size screening. The different heat stabilities of the applied materials lead to a sequential separation. The result is a tantalum powder with a Ta grade of $16 \%$. A total recovery rate of $70 \%$ is claimed by the authors.

A completely different and older approach is given by Stumpf and Seyfart, 1979. Here, capacitors are dissolved in molten aluminum and the remaining tantalum is separated. Other materials like silver can also be recovered.

All the studies presented describe initial approaches for the identification, liberation, separation, and concentration of tantalum from capacitors applied to PCBs. But full recovery is not possible yet. In particular, identification and separation are challenging. Therefore, this study focuses on the outputs of manual separation, which represents the safest methodology. Particularly worthwhile equipment types for successful recycling will also be evaluated.

\section{Materials and Methods}

\section{Disassembly trials}

In this study, a total of over 600 WEEE components belonging to mobile phones, smartphones, tablets, notebooks, desktop PCs, hard disk drives, flat screen monitors, and servers were investigated with disassembly trials regarding their capacitor content. The devices were chosen according to an expected high tantalum capacitor content and a high share of new EEE put-on-market (Chancerel et al. 2013, 2015). A complete overview of a total of ten component types is supplied in the supporting information section S5.

The tantalum capacitors were visually identified by shape, color, and coding. A crucial characteristic for identification is the dash on the surface of the capacitor, indicating the plus and minus 
connectors. Example photos of the most common surface-mounted yellow and black tantalum capacitors are shown in the supporting information section $\mathrm{S2}$.

As capacitors were removed after a visual evaluation of each PCB, the term "visually identifiable tantalum capacitor" (VIC) for the separated target fraction will be used.

For each device, a recycling-oriented product characterization was carried out (Chancerel and Rotter 2009; Rotter et al. 2013). The product masses, the number of PCBs, PCB masses, the number of VICs per PCB, and the VIC masses were determined by both weighing and counting. Furthermore, the year of production was assessed for each single device. This was done either by accessing the production date on the unit or PCB with imprints or via the product names or model number of the PCB.

The devices investigated were classified into UNU-Keys, as developed by the United Nations Universities, Institute for the Advanced Study of Sustainability (Baldé et al. 2015).

\section{Chemical analyses}

In order to assess both element specific separation and the selectivity of VIC removal trials the elemental compositions of the VICs and the PCBs after capacitor removal were analyzed chemically. This allowed the precision of capacitor separation to be assessed. The remaining tantalum content on the PCB and the transferred precious or other metals connected to a capacitor separation were quantified. The chemical composition of VIC and PCB was assessed using the methodologies described in the following paragraphs.

After VIC removal, the PCBs of all devices per equipment type investigated were merged into one mixed sample in order to obtain a maximum sample size for a wet-chemical analysis. This was also carried out for the VIC sample, which consists of all VIC taken from all equipment types. The chemical analysis took place in two different laboratories. As the sample sizes for smartphones and tablets were too small for laboratory 1 , their PCBs were analyzed in laboratory 2. Supporting information section $\mathrm{S} 6$ shows all sample sizes and the laboratory responsible for the relevant measurements. 
Each PCB sample and the mixed VIC sample processed by laboratory 1 underwent a shredding process with dust capture, followed by a fire-assay procedure (collection of $\mathrm{Pb}$ ), followed by analysis with ICP-AES (inductively coupled plasma - atomic emission spectroscopy), ICP-MS (inductively coupled plasma - mass spectrometry) and XRF (X-ray fluorescence). In addition to determining tantalum content, 35 more elements were analyzed, such as the precious metals $\mathrm{Au}, \mathrm{Ag}, \mathrm{Pt}$ and $\mathrm{Pd}$.

The two PCB samples processed by laboratory 2 were first prepared using a shredding process that generated two fractions of different grain sizes. The coarse material consisted of hard metals, which were not shreddable, and was separated prior to the milling step. It was then transferred to a liquid phase by an open aqua regia digestion. The other, finer, material was milled and processed in both a fluxing digestion after an incineration of volatile organic compounds at $550^{\circ} \mathrm{C}$ and a microwave assisted digestion with aqua regia. The measurements were carried out with an ICP-OES and ICP-MS. In total, the mass fractions of 54 elements were determined.

In addition, the loss of ignition for all samples was determined.

\section{Data processing}

In order to calculate the specific transferred masses of target metals with separated VICs and with the PCB residue, equations (1), (2) and (3) were used.

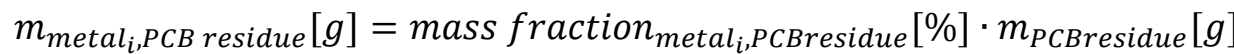

$m_{\text {metal }_{i}, V I C}[g]=$ mass $_{\text {fraction }}$ metal $_{i, V I C}[\%] \cdot m_{V I C}[g]$

$m_{\text {metal }_{i}, P C B}[g]=m_{\text {metal }_{i}, P C B}$ residue $[g]+m_{\text {metal }_{i}, V I C}[g]$

With:

$\mathrm{m}_{\text {metal } \mathrm{i}, \mathrm{PCB} \text { residue }}=$ total mass of metal $\mathrm{i}_{\mathrm{i}}(\mathrm{load})$ to be calculated in the PCB residue after $\mathrm{VIC}$ removal in $\mathrm{g}$

mass $_{\text {fraction }}$ metal $i, \mathrm{PCB}$ residue $=$ mass fraction of metal $_{i}$ in the analyzed $\mathrm{PCB}$ residue in $\%$

$\mathrm{m}_{\mathrm{PCB} \text { residue }}=$ total mass of $\mathrm{PCB}$ residue analyzed after $\mathrm{VIC}$ removal in $\mathrm{g}$

$\mathrm{m}_{\text {metal } \mathrm{i}, \mathrm{VIC}}=$ total mass of metal ${ }_{\mathrm{i}}$ (load) to be calculated in the separated VIC in $\mathrm{g}$

mass $_{\text {fraction }}$ metal $i$, VIC $=$ mass fraction of metal ${ }_{i}$ in VIC analyzed in $\%$ 
$\mathrm{m}_{\mathrm{VIC}}=$ total mass of VIC analyzed in $\mathrm{g}$

$\mathrm{m}_{\text {metal }}, \mathrm{PCB}=$ total mass of metal $_{\mathrm{i}}($ load) to be calculated in the PCB including the VIC in $g$

Selectivity is defined by the concentration of focus materials in a desired output by a separation process. Therefore, removal of the VICs transfers the whole tantalum content of a PCB into a separated fraction. In contrast, other materials like precious metals are supposed to stay on the PCB. In this study, selectivity for each precious metal and tantalum was calculated according to equations (4) and (5)

selectivity $_{\text {metal }_{i} ; t b s}(\%)=\frac{m_{\text {metal }_{i}, V I C}[g]}{m_{\text {metal }_{i}, P C B_{\text {residue }}+V I C[g]}}$

selectivity $_{\text {metal }} ; n t b s[\%]=1-\frac{m_{\text {metal }_{i}, V I C}[g]}{m_{\text {metal }_{i}, P C B}[g]}$

With:

selectivity metal $i$, tbs $_{\text {s }}$ selectivity of metal ${ }_{i}$, which is meant to be separated with a removal of VIC in \%

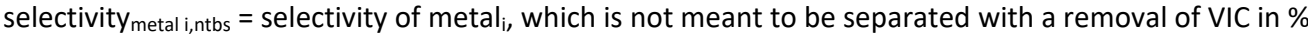

Following this analysis, the total tantalum content of the PCB and the tantalum content potentially recoverable through a removal of the tantalum capacitors is calculated using the average amount of tantalum capacitors for each device and the average tantalum content.

Analysis of the recycling and POM potential

Recycling potentials of relevant devices put-on-market (POM) and WEEE devices collected for recycling purposes were assessed. Based on available data, system boundaries were chosen for Germany and worldwide for the year 2013. For this analysis literature and data from statistical institutions have been reviewed. To assess the linked tantalum masses, sub-calculations were executed following supporting information section S7.

Calculations are based on the average equipment data of PCB masses, the share of PCB and tantalum capacitors in the related equipment, the mass fraction of tantalum in the tantalum capacitors, 
market data on relevant sold equipment types in Germany and worldwide, and data about collected WEEE devices in Germany.

\section{Error propagation}

All calculations in this study have been carried out using corresponding uncertainties with appropriate error propagations. Measurement uncertainties were assessed through the chemical analyses carried out on the VIC and PCB samples. On this basis, the chemical compositions and the selectivity of tantalum were calculated.

Calculations and error propagations for the recycling and POM potential of tantalum relate to a consecutive structure (cf. supporting information section S7). Here, necessary information originates from the chemical analyses or disassembly studies with corresponding uncertainties.

Correlations between the parameters mass per device, mass per PCB and mass of VIC per PCB have been assessed. Distributions were modeled as normal and mathematically independent. A Gaussian error propagation, partially simplified with Goodman's expression, was used.

\section{Analysis of recycling barriers}

A circular economy for all CRM is desirable, but material or product properties and general boundary conditions influence the need for recovery, as well as economic and technical feasibility. In order to evaluate potential opportunities and risks for the recycling of tantalum from VICs, an analysis of barriers and drivers, which support or limit the recycling of tantalum from VICs, was carried out following Rotter et al. (2015, 2016a). Here, all boundary conditions regarding product related properties, available and used technology for liberation, separation and refining of the material as well as economic parameters were considered. A full presentation of the elements investigated is given in the supporting information section S4.

The factors identified were categorized in a modified SWOT (strengths, weaknesses, opportunities, and threats) matrix. While a normal SWOT analysis differentiates between internal and external impacts, a consistent classification of recycling barriers and drivers to the SWOT groups is not 
possible. Barriers to tantalum recycling may give rise to opportunities and have a positive environmental or economic impact and drivers may lead to unwanted side effects.

\section{Results}

PCB and VIC content in different device categories

The mass fractions and total masses of tantalum in different equipment types were analyzed and the elemental mass fractions of a combined VIC sample and combined PCB samples per equipment type investigated after VIC removal were determined.

Figure 1 shows PCB masses per device, VIC masses per device and mass fractions of VICs applied on PCBs, taking the example of mobile phones and laptops. For each data set a histogram and a boxplot have been produced. The boxplots consist of a median, an interquartile range (IQR) between $25 \%$ and $50 \%$ and whiskers within 1.5 times of IQR. Depending on the data, whiskers can also end with the last value between the quartile and 1.5 IQR. Furthermore, outliers are marked with dots. The results for smartphones, tablets, desktop PCs, servers, graphic cards, hard disk drives (HDD), and flat 
screen monitors are summarized in the supporting information section S8.

Mobile phones ( $n=59)$; UNU=306-01
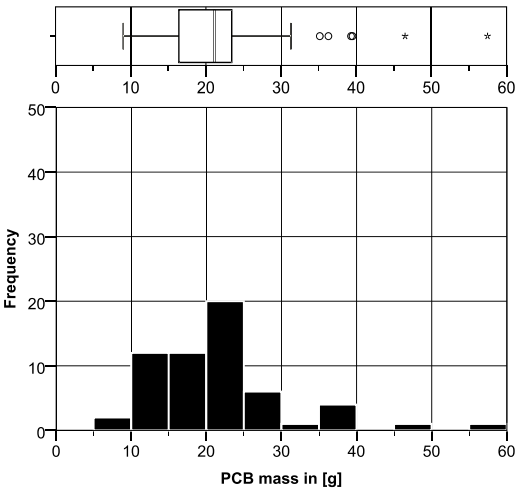

Notebooks mainboard $(n=90) ;$ UNU=303
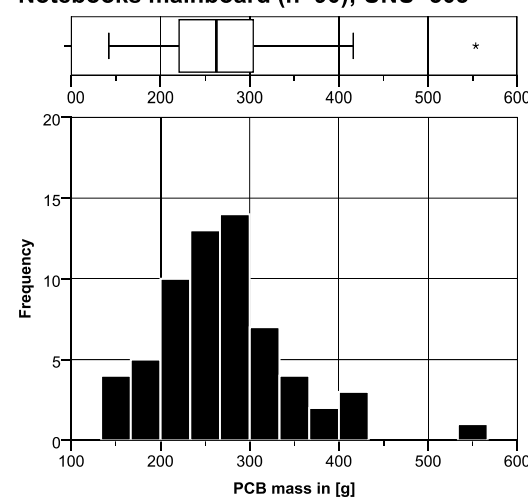
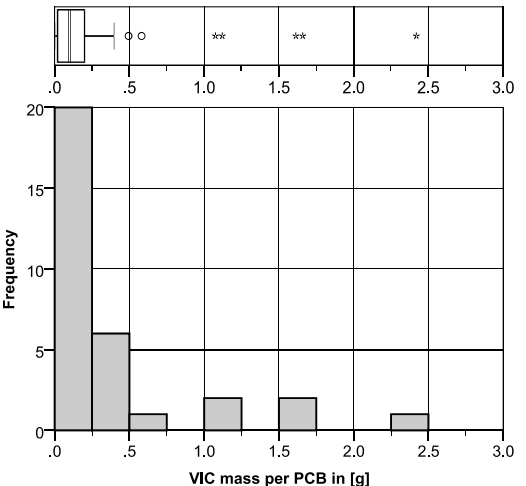

VIC mass per PCB in [g]
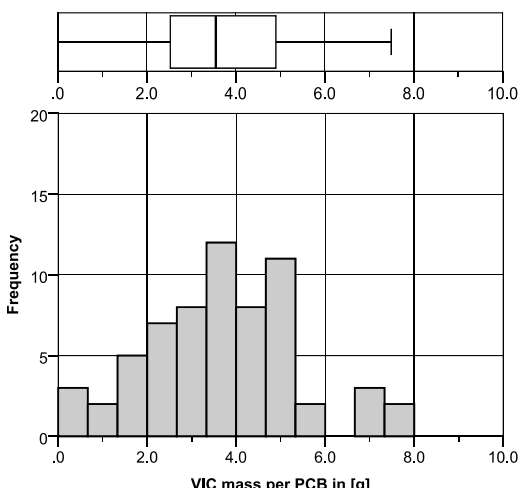
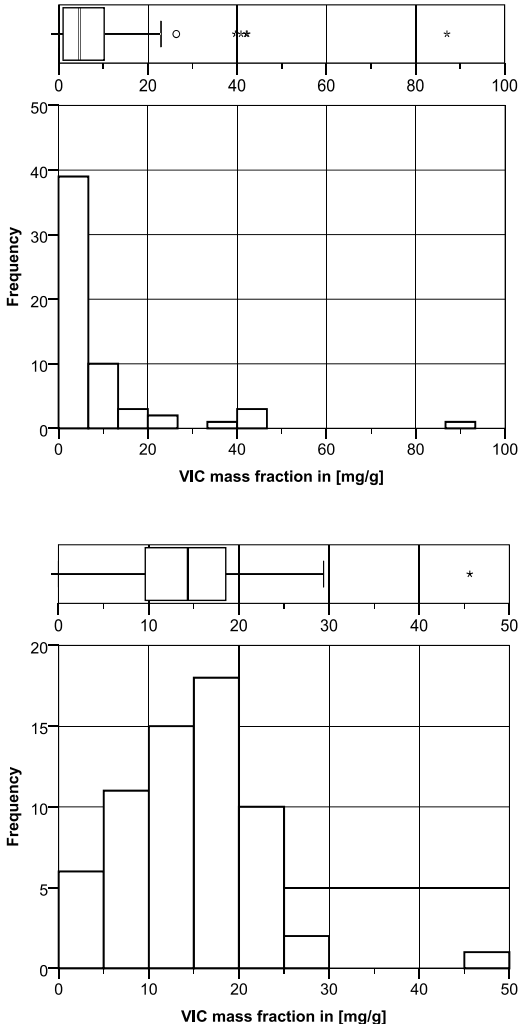

Figure 1: Printed circuit board (PCB) mass per device (left), visually identifiable tantalum capacitors (VIC) per device (middle) and VIC mass fraction per PCB (right) for mobile phones and notebooks. With interquartile range (25/75 \%); whiskers 1.5 $I Q R ;$ asterisk = extremum; circle = outlier .

The amounts of tantalum and the weight of the assembled PCBs vary significantly. The values of the VIC mass per device and per PCB are generally lower for mobile phones than for notebooks. The distribution of VIC mass per device and VIC mass per PCB is strongly shifted to small values for mobile phones, while values are more evenly distributed for notebooks.

This leads to a more sophisticated data processing and statistical evaluation. For non-normal (Gaussian) distributions, expectation values, uncertainties, etc. have to be determined through distribution fittings and the application of appropriate calculation models for each equipment type (Korf 2016).

In general, the highest number of VICs is found on the main PCBs of notebooks and on the PCBs from server devices, which showed the highest median with about 30 VICs per PCB. In the samples 
investigated, VICs were found on a high fraction of PCBs, whereas a larger fraction of PCBs from other equipment held no VICs. The average number of VICs is also low for these devices.

Smartphones and tablets contain the lowest amounts of VICs (median $=1)$. A total overview of the number of VICs per device type is shown in the supporting information section S9.

\section{Assessment of VIC composition}

All VICs separated from the equipment types investigated were analyzed as a mixed sample in order to obtain an overall mass fraction for tantalum, precious metals, and other substances. Figure 2 shows the results of the chemical analyses of the VIC sample. The depicted values represent the average mass fraction per element and the related uncertainty given by the measurement uncertainty. Full analysis results are attached in the supporting information section S10.

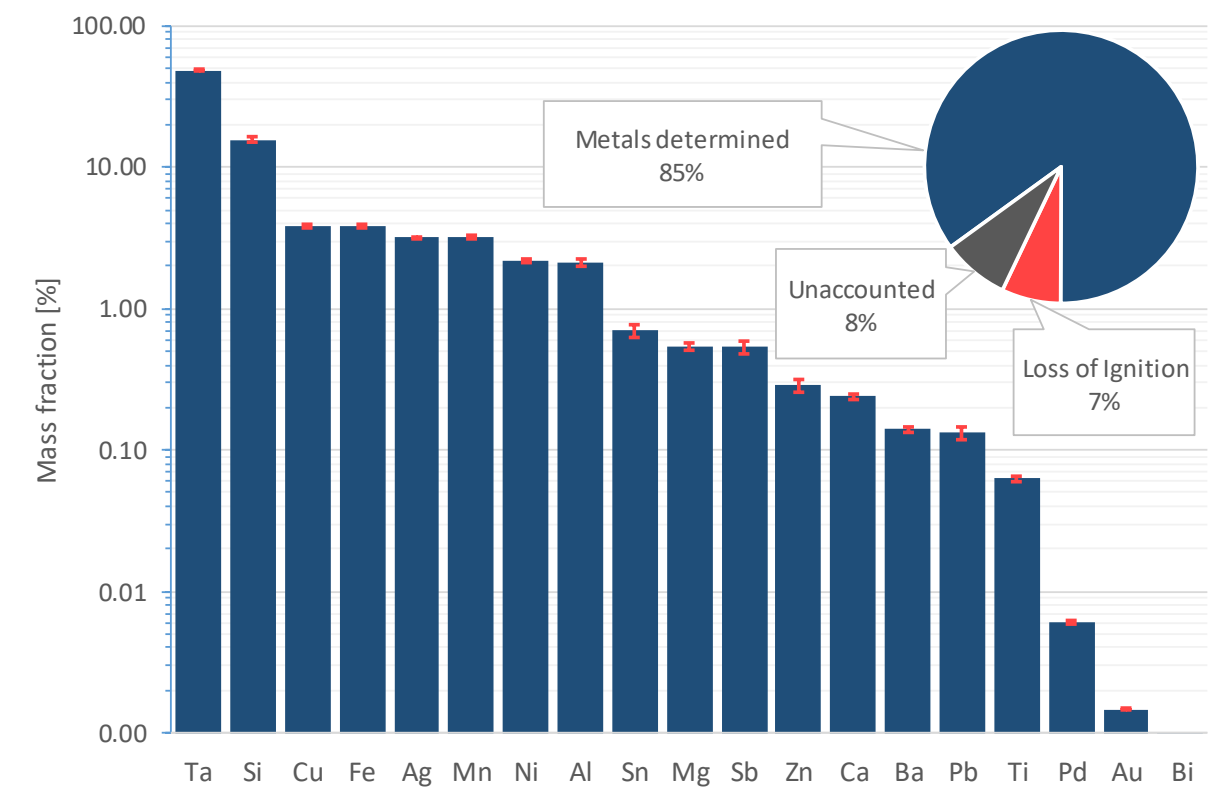

Figure 2: Elemental composition of visually identifiable tantalum capacitors (VIC) (LOI: Loss on ignition. Unaccounted: Share of elements not determined in the analyses; error bars show measurement uncertainty)

The inset in Figure 2 shows the amount of metals determined in the analyses in relation to the total mass of the sample. In addition to loss of ignition (LOI), the total fraction of identified contents was nearly $92 \%$. The LOI is most probably caused by the shell of the capacitors, which is composed of a fire-proof resin, and on the graphite material in the core of the capacitor. 
The average tantalum content is $48.5 \pm 0.5 \%$, a figure in line with the $40 \%$ - $50 \%$ cited by the Tantalum-Niobium International Study Center (T.I.C.), whose data is based on a rough estimation using the number of tantalum capacitors sold and the amount of tantalum grade powder (Schwela 2010). Other studies also show results in the same range (Spitczok von Brisinski et al. 2014; Kwon et al. 2016). This verifies the quality of VIC separation and can be used for further calculations.

In addition to tantalum, major contents are silicon, aluminum, copper, iron, manganese, nickel, and a surprisingly high content of silver with a mass fraction of $3.2 \pm 0.04 \%$. Hence, considering their scarcity and market value, target elements for possible recycling are manganese, silver, and tantalum. Silicon, copper, iron, nickel, and aluminum contents are comparably low and not suitable for a single metal or mixed metal recycling process.

\section{Assessment of separation trials}

The removal of VICs does not transfer the total content of tantalum available on PCBs to a separate stream. Apparently, depending on their properties, not all applied tantalum capacitors can be identified. Furthermore, use of Ta in other components on a PCB is possible. Therefore, chemical analyses for the separated VICs and the remaining PCBs have been carried out (cf. supporting information section S10 and section S11).

Figure 3 shows the resulting tantalum mass fraction per PCB and product type differentiated by the origin of the tantalum. The variations in results are much higher for $\mathrm{g}$ per product and are depicted in a logarithmic scale. 

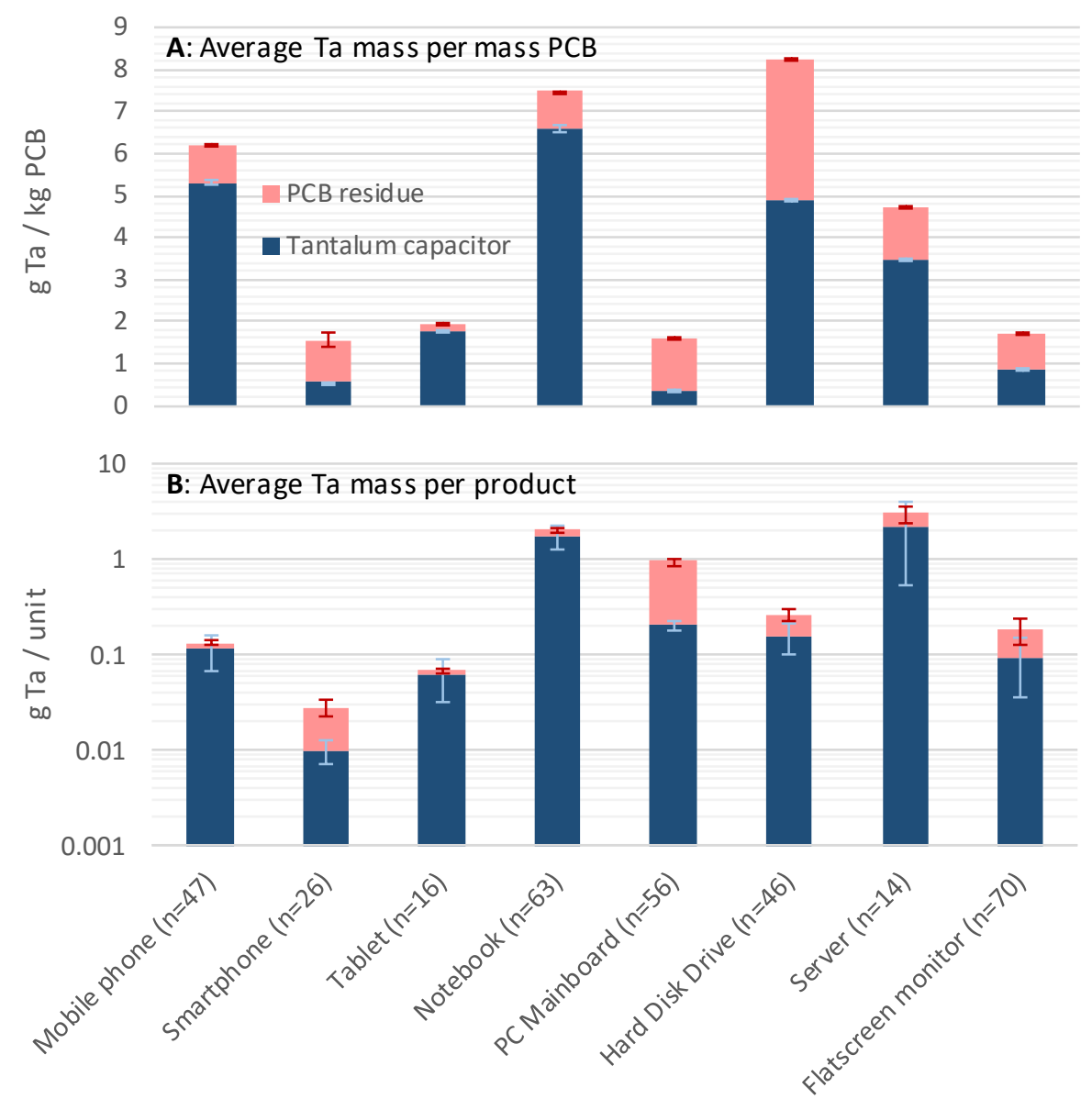

Figure 3: Average tantalum content per mass printed circuit board (PCB) [A] and product [B]. Error bars show standard deviation

Across almost all devices investigated most tantalum was found in the VICs. Depending on the equipment type, different uncertainties for the separation of tantalum are given.

PCBs from notebooks display the highest overall tantalum content determined in PCBs (PCB including VICs) of almost $8 \mathrm{~g} / \mathrm{kg}$ PCB. Furthermore, high levels can also be found in HDDs, servers, and mobile phones. HDDs contain the highest overall Ta content. Here, the PCB residues still have a tantalum load of $3 \mathrm{~g} / \mathrm{kg}$ PCBresidue. Therefore, the total content is over $8 \mathrm{~g} / \mathrm{kg}$ PCB including VICs.

In smartphones and desktop PC mainboards, levels of Ta in PCB residues are higher than in the separated VICs. In contrast, very low overall Ta content was found in smartphones, with $1.5 \mathrm{~g} / \mathrm{kg}$ $\mathrm{PCB}$, and in PC mainboards and flat screen monitors, with $1.6 \mathrm{~g} / \mathrm{kg} \mathrm{PCB}$. These figures are based on a 
considerably fluctuating tantalum content per unit, as the mass share of the PCB to the related unit varies, as does the number and mass of applied VICs.

The results show a good correlation with results from other studies. Fujita et al., 2014 determined about $1 \mathrm{~g} / \mathrm{kg}$ PCB for desktop PCs. PCBs from various sources have only minor tantalum concentrations, with about $0.2 \mathrm{~g} / \mathrm{kg}$ PCB (Xuefeng Wen et al. 2005). In comparison, general tantalum grades of coltan range between 0.1 and $0.5 \mathrm{~g} / \mathrm{kg}$ and are much lower than for the PCBs investigated in this study, but correlate well with a mixed PCB input (USGS 2013).

The tantalum content in $\mathrm{g}$ can be calculated relative to the assembled PCB (g Ta per PCB), and also to the whole device (g Ta per device). With this information, the relevance of processing particular equipment types in order to separate the applied VICs can be compared. Highest contents were found in servers with $4-5 \mathrm{~g} / \mathrm{unit}$, followed by notebooks with ca. $1 \mathrm{~g} / \mathrm{unit}$. The tantalum content per unit of the very small PCBs in mobile phones, smartphones, tablets, HDDs, and flat screen monitors was low. Particularly in smartphones and tablets, many fewer VICs are applied.

The overall mass fraction of identified capacitors and hence the total quality of the removal process was investigated. For this, the load of one metal in the VIC and the load of the same metal in the PCB were added together to find total load. The single loads from the two fractions were calculated as a share of this total value. The results are depicted in Figure 4. Here, the contrast in selectivity of tantalum and precious metals (gold, silver, and palladium) for the equipment types investigated is shown. 


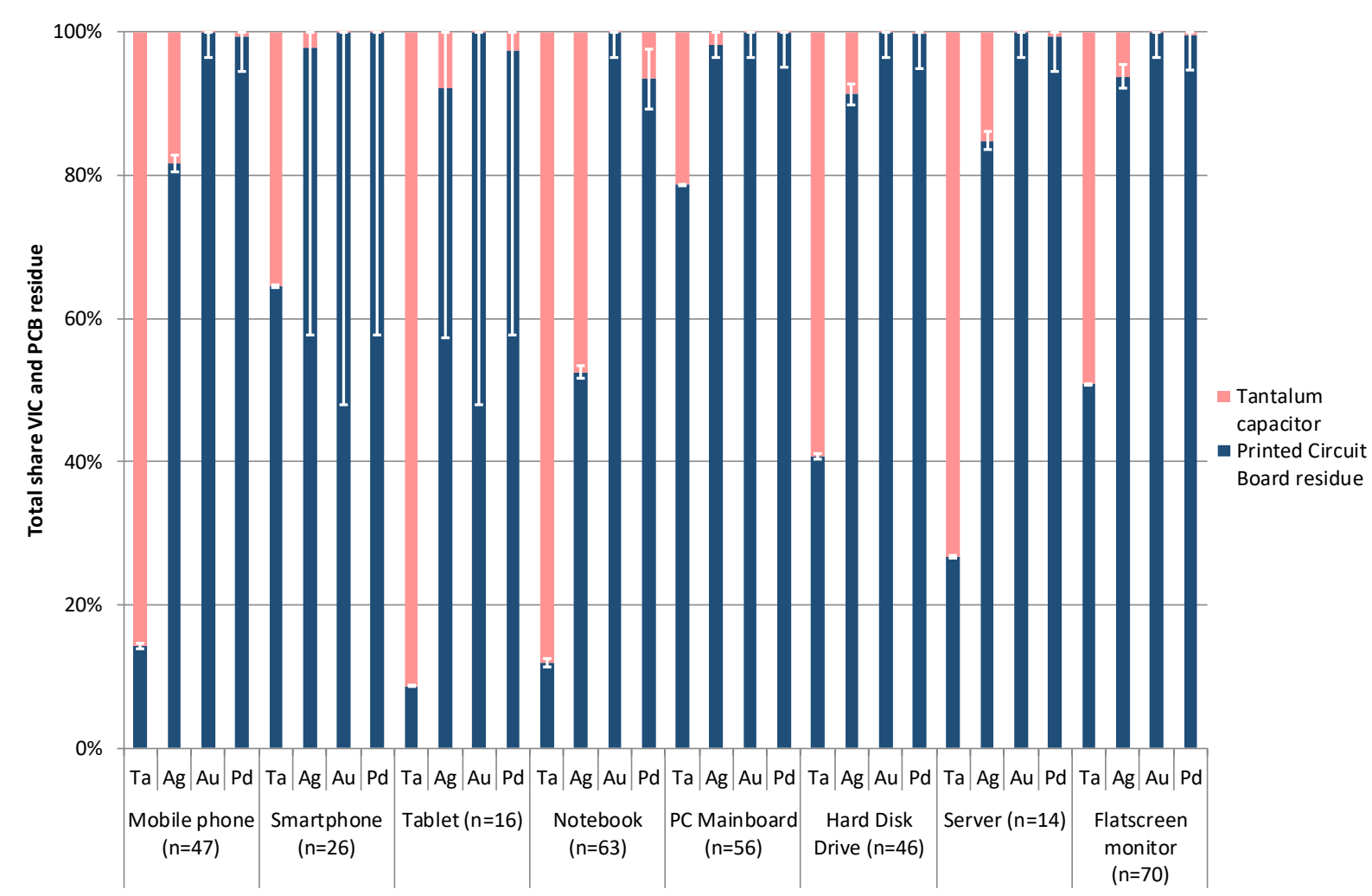

Figure 4: Comparison of the selectivity and retention of tantalum, silver, gold, and palladium (error bars show standard deviation)

The chemical determination of smartphones and tablets was carried out by a different laboratory from the one used for the analyses of the other equipment types. Therefore, other uncertainties related to the methodologies used influenced the results.

The tantalum content in the VIC fraction for tablets, mobile phones, notebooks, and servers is very high, which means a good visual identification of applied capacitors. In contrast, the tantalum load in the separated VICs compared to the load in the PCB residues is very low with under $50 \%$ for flat screen monitors, under $40 \%$ for smartphones and just under $20 \%$ for desktop PCs. This data reveals a very low visual identification and separation quota of Ta bearing components.

In most of the devices investigated a high percentage of the silver applied in the tantalum capacitors is removed. The example notebook shows that up to ca. $50 \%$ of silver can be removed via VIC separation. The lowest mass fraction of silver removed is encountered in desktop PCs and smartphones, for which the mass fraction of separated tantalum is also very low. 
As expected, the separated mass fractions of other precious metals like gold and palladium are low and show that these elements are mainly applied in the residual PCB.

Time trend in the application of tantalum

In order to devise a trend over time of applied tantalum in the equipment types investigated, the mass fractions of VICs were compared to the data gathered on recycling-oriented product characterization. Figure 5 shows a comparison by year of manufacture of the total VIC masses separated from the PCBs per single device investigated. 

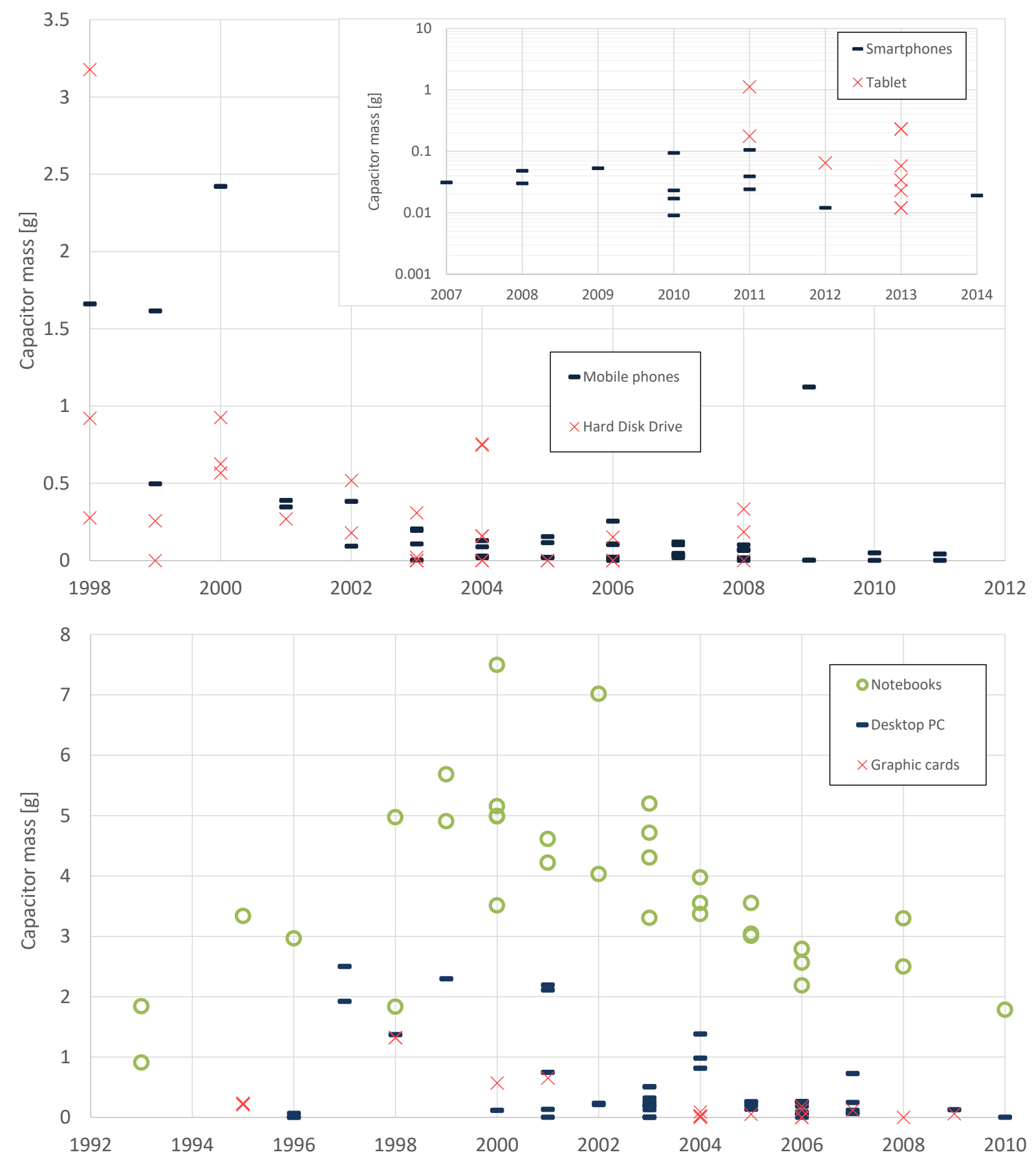

Figure 5: Mass of capacitors per printed circuit board (PCB) of mobile phones, smartphones, tablets, hard disk drives, graphic cards and mainboards from desktop PCs, and notebooks compared by date of manufacture

In general, the total mass of VICs applied decreases over time. This applies to notebooks as well, although an increase in total VIC mass was seen between 1993 and 1999. This may be attributed to the development of computing capacity and an increasing miniaturization of the devices. However, less data is available for these years which may result in an incomplete representation of the total mass of VICs applied. 
A stronger trend is shown for mobile phones, hard disk drives, desktop PCs, and graphic cards. Here, a generally decreasing trend in capacitor mass per PCB and unit is visible.

Smartphones and tablets represent a very young generation of mobile devices. Since these equipment types are still in the market saturation phase (particularly tablets), figures are available only for the years between 2007 and 2014. In the case of tablets, data is available for only three years. Development in product technology may be less over this short time span. Therefore, variations in VIC content are also low.

\section{Selectivity tantalum and silver}

The surprisingly high content of silver in tantalum capacitors was investigated in more detail, in order to check the impact of the removal of VICs on the recycling efficiency of silver, applying established processes on the entire PCB. The results of a comparison of the selectivity of tantalum and silver through VIC removal are shown in Figure 4 and covered in more detail in supporting information section S13.

It is obvious that selective removal of tantalum is not possible for all the equipment types investigated. Silver is always applied in tantalum capacitors and is therefore removed with the VICs. The mass fraction of the silver removed compared to the total content of silver is dependent on the $\mathrm{PCB}$ of the equipment type investigated and on the number and weight of applied tantalum capacitors.

The trend of silver separation alongside VIC removal is positive. In other words, the higher the amount of VIC separation, the higher the amount of silver removal. Therefore, regular removal of VICs for purposes of tantalum recycling would lead unavoidably to a loss of silver. Interviews with tantalum producers, who also recycle new scrap, reveal that recycling of both tantalum and silver is not yet possible or economic (Marwede et al. 2015; H.C. Starck 2011) . 
A good example of this is notebooks. Here, a high selectivity of tantalum meets a relatively low selectivity of silver with only $50 \%$. This means that a large percentage of the total silver available is transferred to the VIC fraction.

This has to be taken into account in any development of recycling processes as capacitor removal may interfere with the operating efficiency of established PCB recycling processes. The establishment of a recycling infrastructure for tantalum from capacitors requires the development of side-by-side recovery processes for tantalum and silver.

\section{Recycling potential}

In addition to the technical demands for the recycling of tantalum bearing capacitors, sufficient material input must be available for recycling purposes. Recycling potential based on the mass fractions of tantalum in the equipment types investigated was calculated. For this, the return flows of relevant equipment types collected in Germany for recycling purposes was investigated for the year 2013. The results reveal a total of $6 \pm 1 \mathrm{Mg}$ of collected tantalum capacitors and subsequently $3 \pm 1 \mathrm{Mg}$ of tantalum.

In contrast, the put-on-market (POM) data differs. This is important for developing a circular economy as secondary tantalum will be able to meet the production needs of new electric and electronic goods. In Germany in 2013, the POM figures were $39 \pm 7 \mathrm{Mg}$ tantalum capacitors and $19 \pm 3$ Mg tantalum.

Worldwide POM figures for 2013 were $2,800 \pm 500 \mathrm{Mg}$ of tantalum capacitors and subsequently $1,300 \pm 250 \mathrm{Mg}$ of tantalum.

Figure 6 shows the differentiated collection and POM data for tantalum masses obtained through VIC separation in each equipment type investigated (results for PCB residues and PCBs including VICs are provided in the supporting information section S14 and section S15. The calculation for the data extrapolation is also depicted in section S12.) 


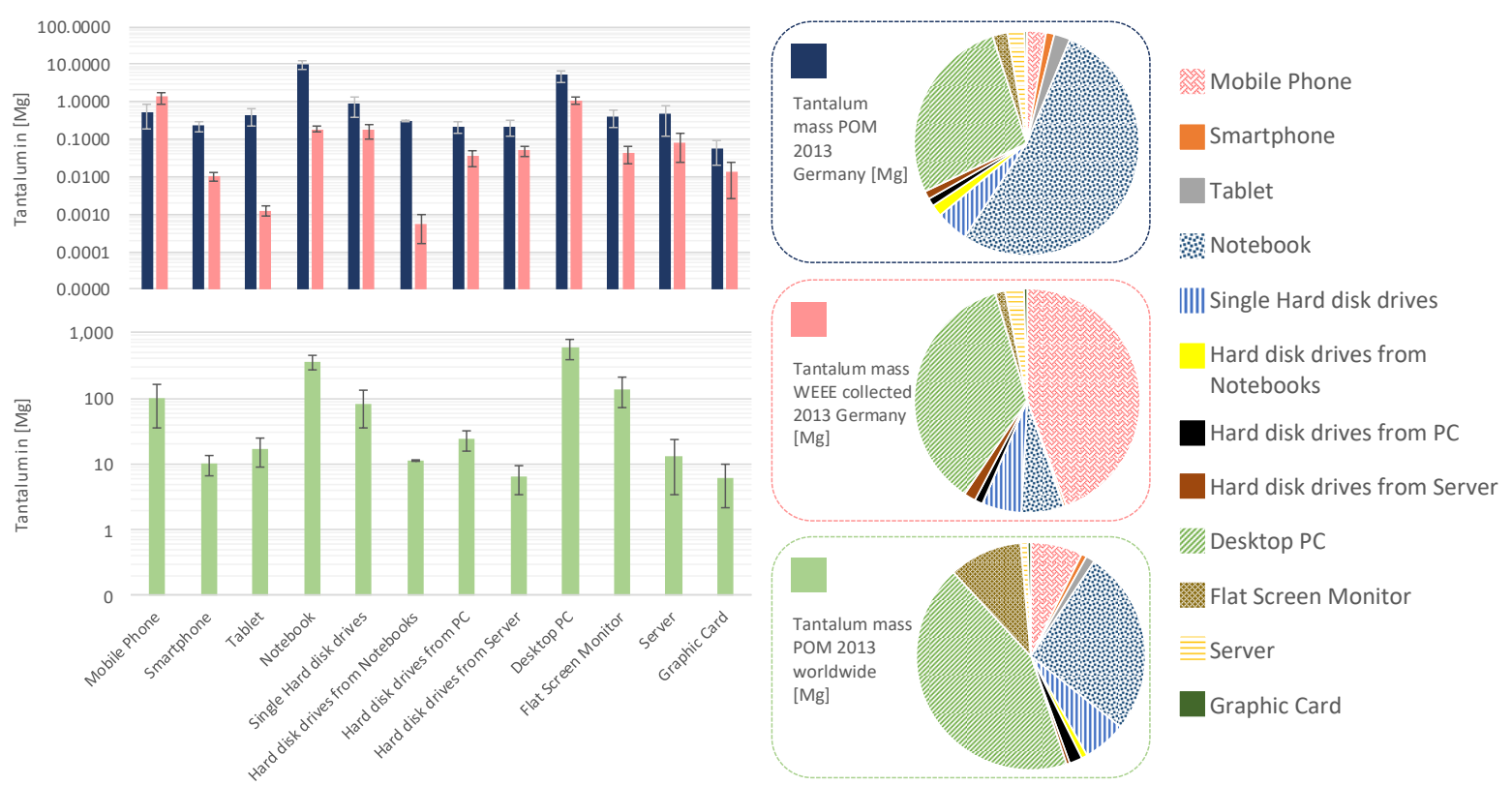

Figure 6: Total tantalum potential through visually identifiable tantalum capacitor (VIC) separation in POM devices (Germany / worldwide) versus WEEE devices collected for recycling purposes in Germany

The highest tantalum collection potential among tantalum bearing devices is found in mobile phones. Although tantalum content in this device type is average for the equipment types investigated, high collection rates lead to high availability of tantalum masses. Mobile phones constitute an exception as POM tantalum masses are generally lower than those of WEEE. This is because of a shift in technology. The market for mobile phones is shrinking while the market for smartphones is increasing and significant quantities of smartphones are not yet being collected. As a result, the gap between tantalum masses for POM and for collection is high. This also applies to tablets. Therefore, smartphones and tablets, as well as HDDs from notebooks, have the lowest potential for tantalum collection.

Tantalum masses linked to POM devices in Germany and worldwide have almost the same distribution. Highest potentials are connected to notebooks and desktop PCs. The lowest potentials are calculated for servers and associated HDDs as well as smartphones and tablets.

This data applies only for the year 2013. Depending on market shifts, the potentials can change significantly. 
The POM and returned tantalum flows are closely connected to the composition of sold or collected equipment types with accordingly different loads of tantalum. In order to compare this distribution, Figure 6 also shows the relevant shares for tantalum POM and collected in 2013 in Germany and POM worldwide. This data is based only on tantalum flows through VICs. The distribution for PCB residues and PCB including VIC are shown in the supporting information sections S14 and $\underline{\text { 115. }}$.

Due to high sales of notebooks in Germany in 2013 ( $\sim 5$ million devices), the share of tantalum POM is dominated by this type of equipment. Although sales of smartphones are much higher ( 22 million devices), the contribution of these tantalum flows is only about $1.2 \%$ due to the low number of applied VICs. In contrast, the tantalum flows collected for recycling purposes are dominated by mobile phones. Background data is given in the supporting information section S12.

The tantalum load from PCB residues is partially higher than in the separated VICs. This applies, for example, to smartphones and desktop PCs. For HDDs and flat screen monitors the ratio of tantalum in PCB residue and VICs is almost the same. Therefore, tantalum flows related to PCBs and VICs in POM and WEEE must be distinguished from each other. A comparison of all equipment types investigated, except for graphic cards, is shown in supporting information section S16.

\section{Discussion}

\section{Comparison with theoretical estimates on literature basis}

The data generated reveals high variations in the use of tantalum in the equipment types investigated. Here, a comparison with given literature data is useful. For validation, a comparison of POM data was carried out. Chancerel et al. (2015) summed up the information from various sources in order to calculate the POM tantalum flows for various equipment types. The data is given as a range. As the data in this study is calculated with standard deviations, the comparison is only indirectly possible (cf. Table 1). 
Furthermore, the global tantalum POM for similar devices was compared to the capacitor-grade tantalum powder shipments (cf. supporting information section S3). This raw material represents a high-grade powder specifically formulated for the production of tantalum capacitors.

Table 1: Comparison of total tantalum flows [printed circuit board (PCB) including visually identifiable tantalum capacitors (VIC)] per equipment type through put on market (POM) devices in Germany and worldwide as well as shipments of tantalum powder for capacitors

\begin{tabular}{|c|c|c|c|c|c|c|c|c|c|}
\hline \multirow[b]{2}{*}{$\begin{array}{l}\text { Values } \\
\text { in Mg }\end{array}$} & \multicolumn{7}{|c|}{ Tantalum flows Germany POM } & \multicolumn{2}{|c|}{ Flows worldwide } \\
\hline & $\begin{array}{l}\text { Mobile } \\
\text { phone }\end{array}$ & $\begin{array}{l}\text { Smart- } \\
\text { phone }\end{array}$ & Tablet & $\begin{array}{c}\text { Desktop } \\
\text { PC }\end{array}$ & $\begin{array}{l}\text { Notebook } \\
\text { (all back- } \\
\text { lighting) }\end{array}$ & $\begin{array}{c}\text { Flat } \\
\text { screen } \\
\text { monitor }\end{array}$ & $\begin{array}{c}\text { POM } \\
\text { devices } \\
\text { total }\end{array}$ & $\begin{array}{c}\text { POM } \\
\text { devices } \\
\text { total }\end{array}$ & $\begin{array}{c}\text { Ta } \\
\text { powder } \\
\text { for caps }\end{array}$ \\
\hline 2007 & $2-9^{1}$ & $0.1-0.6^{1}$ & $0-0^{1}$ & $2-12^{1}$ & $3.5-17^{1}$ & $0.5-2.5^{1}$ & $25 \pm 9^{1}$ & & $920^{3}$ \\
\hline 2012 & $0.1-1^{1}$ & $0.6-6^{1}$ & $0.2-1.5^{1}$ & $0.7-7^{1}$ & $2.3-23^{1}$ & $0.1-0.4^{1}$ & $22 \pm 11^{1}$ & & $500^{3}$ \\
\hline 2013 & $0.6 \pm 0.3^{2}$ & $0.6 \pm 0.2^{2}$ & $0.5 \pm 0.2^{2}$ & $6.4 \pm 1.8^{2}$ & $11 \pm 2.6^{2}$ & $0.8 \pm 0.3^{2}$ & $19 \pm 3^{2}$ & $1,300 \pm 250^{2}$ & $540^{3}$ \\
\hline
\end{tabular}

Note: data tantalum flows based on ${ }^{1}$ Chancerel et al. (2015), ${ }^{2}$ own data, and ${ }^{3}$ Tantalum-Niobium International Study Center (2011, 2013b, 2013a, 2016) for primary raw materials in the form of Ta powder for capacitors

The literature data for POM devices in Germany refers to the years from 2007 to 2012. A more reasonable comparison for the data in this study would be the year 2012 , although there might be a continuing trend of increasing or decreasing flows related to particular equipment types. Except for flat screen monitors, the actual data from 2013 complies with the literature data. The generated data specifies the information available on various levels.

There is a noticeable negative trend to the total tantalum POM with comparable devices in Germany. An opposite trend is drawn by the total shipments of tantalum powder for capacitors. The peak period for shipments was between 2006 and 2008, with over $900 \mathrm{Mg}$ per year. This dropped by half in 2009, but shipments show an average increase since then. The most up to date values available are for 2014, with $635 \mathrm{Mg}$ (cf. supporting information section S3).

\section{Tantalum recycling and processing}

Industrial scale tantalum recycling is usually based on input material with high purity such as production scrap. This material has to be processed and cleaned using mechanical and 
hydrometallurgical approaches in order to separate the tantalum from undesired materials like plastics or even niobium (H.C. Starck 2009, 2011). As these processes are complex and costly, usually only post-industrial scrap is used. Recycling of tantalum in separated VICs is not feasible with current recovery strategies (Rotter et al. 2016b). A restructuring of the processes might be necessary. Based on data presented in this study, the first economically feasible approaches can be derived.

Corresponding concepts which can handle capacitors from WEEE products have been shown.

Furthermore, current recycling processes cannot recover the applied silver in the capacitors. This should be considered when setting up new systems for the recovery of tantalum from VICs. The recyclability of precious metals depends on the processes used and could be implemented with changes in the recycling system.

\section{Analysis of recycling barriers}

Low retail prices of metals combined with technically demanding processes impede the development of circular economy approaches for CRM. Tantalum in particular shows the importance of CRM in modern EEE products, but also the challenges for their recycling. Table 2 lists the results obtained from the recycling barriers analysis.

Table 2: Analysis of recycling barriers for tantalum in visually identifiable tantalum capacitors (VIC)

\begin{tabular}{|c|c|c|c|c|c|c|}
\hline & \multicolumn{4}{|c|}{ Strength } & & Weaknesses \\
\hline
\end{tabular}

VICs analyzed consist almost half of tantalum. Plastics, silicon, copper, iron and silver represent other major materials. This simple design facilitates recycling processes. Usually, VICs on PCBs are directed 
to copper smelters with subsequent precious metals refining. Recovery of tantalum in this process is not feasible. But VICs contribute to this process due to copper and silver contents. A prior separation is crucial for the recovery of tantalum, but would lower the value of the PCB and lower slightly the overall efficiency of the refining process. Economically feasible technologies for the identification and separation of VICs are not yet available. Recovery processes for tantalum in VICs do exist, but are related to high energy and chemicals input.

Investigated WEEE products showed an uneven distribution of VICs. Therefore, a focus on particular products leads to higher yields in recycling. However, the use of VICs seems to be decreasing.

Miniaturization of tantalum capacitors will further reduce total tantalum loads and value. Moreover, due to its criticality, initial approaches have been made to substitute tantalum with niobium. This might reduce the need for a circular economy for tantalum in a long-term perspective.

\section{Conclusion}

Tantalum capacitors analyzed in this study comprise only visually identifiable capacitors, classified by known characteristics. Removal of these VICs does not separate the total tantalum content. For flat screen monitors and hard disk drives, the separation rate is under $60 \%$. For smartphones and desktop PCs, the ratio is much lower. Therefore, a reliable separation of all tantalum with VICs is not possible.

With separation of VICs, up to $50 \%$ of total silver content is also removed. This is because of the design of the VICs and the application of silver connectors. This implies a major recycling conflict as either only tantalum or only silver can be recovered with current recycling technologies.

In order to obtain sufficient input masses for tantalum recycling, relevant equipment types have to be identified and bundled. The highest potential of tantalum per unit was found in notebooks and servers with over $1 \mathrm{~g}$ Ta. In contrast, the highest potential in PCBs is in hard disk drives (over $8 \mathrm{~g} / \mathrm{kg}$ PCB), notebooks, and mobile phones. The smartphones and tablets investigated have the lowest quantities and are not suitable for an economically driven recycling of tantalum. 
Depending on market shares and collection rates of particular equipment types, what comprises a fruitful source of Ta can shift. Because of the availability of collected WEEE devices in Germany in 2013, mobile phones and desktop PCs provide the highest tantalum loads.

The findings of this study show generally low shares of tantalum in PCBs from modern IT devices. Major loads are related to tantalum based capacitors, which are applied in EEE in a variety of forms and represent the major application of tantalum in the electronics sector. A recycling of tantalum from these components is possible. But the methodologies discussed do not represent a long-term strategy, as an accurate separation of tantalum from PCBs is not possible by separation of VICs alone, a process which involves the loss of precious metals. Furthermore, a potential trend for miniaturization and a decrease in applied capacitors and tantalum masses was revealed in this study. Recycling strategies need to be adapted accordingly in the future in order to establish a circular economy for tantalum.

\section{Funding}

This work was funded by the German Federal Ministry of Education and Research (BMBF) (UPgrade Project reference number 033R087A)

\section{Literature}

Baldé, K., C.P. Balde, R. Kuehr, K. Blumenthal, S. Fondeur Gill, M. Kern, P. Micheli, E. Magpantay, and J. Huisman. 2015. E-waste statistics - Guidelines on classification, reporting and indicators. Bonn: ESCAP, ESCWA, ITU, OECD, UNCTAD, UNECA, EUROSTAT, UNEP/SBC, UNU 3.

Buckingham, D.A., L.D. Cunningham, M.J. Magyar, and J.F. Papp. 2014. Tantalum Statistics.

Chancerel, P., T. Bolland, and V.S. Rotter. 2010. Status of pre-processing of waste electrical and electronic equipment in Germany and its influence on the recovery of gold. Waste Management \& Research 29(3): 309-317. http://www.ncbi.nlm.nih.gov/pubmed/20406755. Accessed February 7, 2013. 
Chancerel, P., M. Marwede, N.F. Nissen, and K.-D. Lang. 2015. Estimating the quantities of critical metals embedded in ICT and consumer equipment. Resources, Conservation and Recycling 98(1): 9-18. http://linkinghub.elsevier.com/retrieve/pii/S0921344915000488.

Chancerel, P., C.E.M. Meskers, C. HagelÃ1/4ken, and V.S. Rotter. 2009. Assessment of Precious Metal Flows During Preprocessing of Waste Electrical and Electronic Equipment. Journal of Industrial Ecology 13(5): 791-810. http://doi.wiley.com/10.1111/j.1530-9290.2009.00171.x.

Chancerel, P. and S. Rotter. 2009. Recycling-oriented characterization of small waste electrical and electronic equipment. Waste Management (New York, N.Y.) 29(8): 2336-52. http://www.ncbi.nlm.nih.gov/pubmed/19427188. Accessed February 7, 2013.

Chancerel, P., V.S. Rotter, M. Ueberschaar, M. Marwede, N.F. Nissen, and K.-D. Lang. 2013. Data availability and the need for research to localize, quantify and recycle critical metals in information technology, telecommunication and consumer equipment. Waste Management \& Research 31(10 Suppl): 3-16. http://wmr.sagepub.com/cgi/doi/10.1177/0734242X13499814. Accessed October 11, 2013.

Cunningham, L.D. 2001. Tantalum Recycling in The United States in 1998. U. S. Department of the Interior U.S. Geological Survey.

Cymorek, C. 2015. Personal correspondence. Sen. Mgr. Raw Material Projects Division Tantalum \& Niobium Powders.

European Commission. 2010. Critical raw materials for the EU. Ad-Hoc Working Group on Defining Critical Raw Materials(July): 1-84. http://scholar.google.com/scholar?hl=en\&btnG=Search\&q=intitle:Critical+raw+materials+for+t he+EU\#0. Accessed February 8, 2013.

European Commission. 2014. Report on critical raw materials for the EU. Ad Hoc Working Group on Defining Critical Raw Materials(May): 41. http://ec.europa.eu/enterprise/policies/raw- 
materials/files/docs/crm-report-on-critical-raw-materials_en.pdf.

Fitzpatrick, C., E. Olivetti, T.R. Miller, R. Roth, and R. Kirchain. 2015. Conflict Minerals in the Compute Sector: Estimating Extent of Tin, Tantalum, Tungsten, and Gold Use in ICT Products. Environmental Science \& Technology 49(2): 974-981. http://pubs.acs.org/doi/abs/10.1021/es501193k.

Fujita, T., H. Ono, G. Dodbiba, and K. Yamaguchi. 2014. Evaluation of a recycling process for printed circuit board by physical separation and heat treatment. Waste Management 34(7): 12641273. http://linkinghub.elsevier.com/retrieve/pii/S0956053X14000920.

Graedel, T.E. and B.K. Reck. 2016. Six Years of Criticality Assessments: What Have We Learned So Far? Journal of Industrial Ecology 20(4): 692-699. http://doi.wiley.com/10.1111/jiec.12305.

H.C. Starck. 2009. Umweltgerecht, kompetent, einzigartig. Goslar. https://www.hcstarck.com/hcsadmin/file/8a8181e225548334012554ccf6091424.de.0/Wolfram-Tantal-Niob-Recycling-HCStarck.pdf.

H.C. Starck. 2011. Elektroschrott - Together We Recycling Succeed. In Presentation Slides.

Hatayama, H. and K. Tahara. 2014. Criticality Assessment of Metals for Japan's Resource Strategy. Materials Transactions 56(2): 229-235. https://www.jstage.jst.go.jp/article/matertrans/56/2/56_M2014380/_article.

Hayashi, N. and T. Oki. 2014. Effect of Orifice Introduction on Floating Characteristics of Cuboid Particles Simulating Tantalum Capacitors in Pneumatic Separation Column. MATERIALS TRANSACTIONS 55(6): 952-957. http://jlc.jst.go.jp/DN/JST.JSTAGE/matertrans/MM2014818?lang=en\&from=CrossRef\&type=abstract.

Korf, N. 2016. Distribution patterns of critical metals in electrical and electronic waste. In DGAW 5. Wissenschaftskongress. Berlin, Germany: DGAW.

Kreibe, S. and A. Förster. 2016. Strategische Rohstoffe in Telekommunikations-Netztechnik - Kann 
die Recyclingquote gesteigert werden? In Recycling Und Rohstoffe, Band 9, 361-372.

Neuruppin: Vivis Verlag.

Kwon, S., S. Park, S. Kim, A. Joe, Y. Song, P. Park, and J. Park. 2016. Separation of Tantalum from Electronic Components on Laptop Printed Circuit Board Assembly. Journal of the Korean Institute of Resources Recycling 25(1): 24-30.

http://koreascience.or.kr/journal/view.jsp?kj=RSOCB3\&py=2016\&vnc=v25n1\&sp=24.

Marwede, M., P. Chancerel, M. Ueberschaar, V.S. Rotter, N.F. Nissen, and K.-D. Lang. 2015. Building the bridge between innovative recycling technologies and recycling-friendly product design The example of technology metals. In Global Cleaner Production and Sustainable Consumption Conference.

Mineta, K. and T.H. Okabe. 2005. Development of a recycling process for tantalum from capacitor scraps. Journal of Physics and Chemistry of Solids 66(2-4): 318-321.

http://linkinghub.elsevier.com/retrieve/pii/S0022369704003117. Accessed January 31, 2013.

Oki, T. 2013. Physical separation technology to support the strategic development of urban mining. Synthesiology 6(4): 232-240.

Rotter, V.S., P. Chancerel, and M. Ueberschaar. 2013. Recycling-Oriented Product Characterization for Electric and Electronic Equipment as a Tool to Enable Recycling of Critical Metals. In REWAS 2013, ed. by Anne Kvithyld, Christina Meskers, Randolph Kirchain, Gregory Krumdick, Brajendra Mishra, Markus Reuter, Cong Wang, et al., 192-201. Hoboken, NJ, USA: John Wiley \& Sons, Inc., February 25. http://doi.wiley.com/10.1002/9781118679401.ch21.

Rotter, V.S., S.J. Otto, M. Ueberschaar, and P. Chancerel. 2016a. Resultate aus dem Projekt UPgrade Beispiel Gallium. In Recycling Und Rohstoffe, Band 9, ed. by Karl J. Thomé-Kozmiensky and Daniel Goldmann. Neuruppin: TK Verlag Karl Thomé-Kozmiensky.

Rotter, V.S., M. Ueberschaar, J. Geiping, and P. Chancerel. 2015. Potenziale zum Recycling 
wirtschaftsstrategischer Metalle aus Elektroaltgeräten. In Recycling Und Rohstoffe, Band 8, ed. by Karl J. Thomé-Kozmiensky and Daniel Goldmann, 249-267. Neuruppin: TK Verlag Karl Thomé-Kozmiensky.

Rotter, V.S., M. Ueberschaar, G. Walter, S. Flamme, P. Chancerel, and Marwe. 2016b. Final report UPgrade. Technische Universität Berlin, Institute of Environmental Technology, Chair of Circular Economy and Recycling Technology.

Schwela, U. 2010. The state of tantalum mining. Mining Journal.

Smokovich. 2009. Method for the production of tantalum powder using reclaimed scrap as source material.

Spitczok von Brisinski, L., D. Goldmann, and F. Endres. 2014. Recovery of Metals from Tantalum Capacitors with Ionic Liquids. Chemie Ingenieur Technik 86(1-2): 196-199. http://doi.wiley.com/10.1002/cite.201300059.

Stenzel, M. 2016. Presentation: Tantalum Recycling @ H.C. Starck. Final Workshop - UPgrade Project, Technische Universität Berlin.

Stumpf, H. and G. Seyfart. 1979. Recovery of metals from scrap tantalum capacitors - using molten aluminium to dissolve all metals except tantalum.

Tantalum-Niobium International Study Center. 2011. TIC. In Bulletin N²145, 1-8.

Tantalum-Niobium International Study Center. 2013a. TIC. In Bulletin Nº 153.

Tantalum-Niobium International Study Center. 2013b. TIC. In Bulletin Nº 156.

Tantalum-Niobium International Study Center. 2016. TIC. In Bulletin N²164, 1-31.

UNEP. 2013. Metal Recycling: Opportunities, Limits, Infrastructure, A Report of the Working Group on the Global Metal Flows to the International Resource Panel. United Nations Environmental Programme. Paris. 
http://scholar.google.com/scholar?hl=en\&btnG=Search\&q=intitle:Metal+RECYCLING+Opportun ities,+Limits,+Infrastructure\#0. Accessed June 4, 2014.

USGS. 2013. An Exploration in Mineral Supply Chain Mapping Using Tantalum as an Example. http://pubs.usgs.gov/of/2013/1239/.

Wang, X., S. Zheng, H. Xu, and Y. Zhang. 2009. Leaching of niobium and tantalum from a low-grade ore using a $\mathrm{KOH}$ roast-water leach system. Hydrometallurgy 98(3-4): 219-223. http://linkinghub.elsevier.com/retrieve/pii/S0304386X09001054. Accessed February 8, 2013.

Wickens, J. 2004. Developments in the tantalum market Tantalum-Niobium International Study. In Minor Metals 2004, Presentation Slides.

Xuefeng Wen, Yuemin Zhao, Chenlong Duan, Xiaohua Zhou, Hongguang Jiao, and Shulei Song. 2005. Study on metals recovery from discarded printed circuit boards by physical methods. In Proceedings of the 2005 IEEE International Symposium on Electronics and the Environment, 2005., 121-128. IEEE. http://ieeexplore.ieee.org/lpdocs/epic03/wrapper.htm?arnumber=1437005. 


\title{
Supporting information
}

\section{Potentials and barriers for tantalum recovery from waste electric and electronic equipment}

Maximilian Ueberschaar, Daniel Dariusch Jalalpoor, Nathalie Korf, Vera Susanne Rotter

\author{
Address correspondence to: \\ Maximilian Ueberschaar \\ maximilian.ueberschaar@tu-berlin.de \\ +49(0)30 $314-29136$ \\ Chair of Circular Economy and Recycling Technology \\ Office Z2 \\ Institute of Environmental Technology \\ Technische Universität Berlin \\ Straße des 17. Juni 135 \\ 10623 Berlin \\ Published in Journal of Industrial Ecology
}




\section{Contents}

Section S1: Design of a typical tantalum capacitor

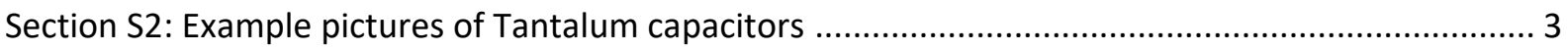

Section S3: Tantalum shipments and price development between 2002 and 2012 ............................ 4

Section S4: Barrier analysis for the recycling of a target material ....................................................... 5

Section S5: Overview of investigated devices and subunits with production years 1993-2014............ 6

Section S6: Overview on sample sizes and laboratories for chemical analyses.................................. 6

Section S7: Sub-levels for the calculation of the tantalum masses based on relevant devices POM and

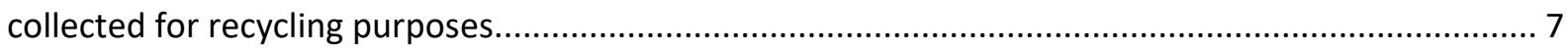

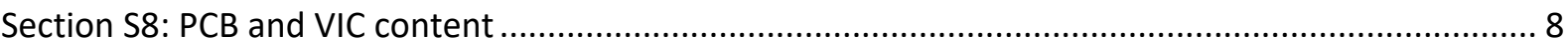

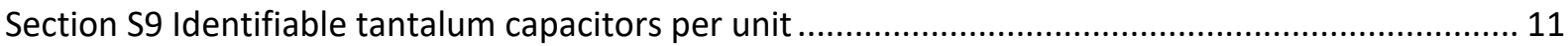

Section S10: Elemental composition of visual identifiable tantalum capacitors ................................. 12

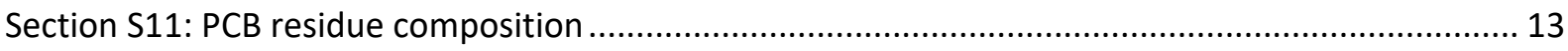

Section S12: Detailed calculation of Tantalum in devices POM and devices collected for recycling

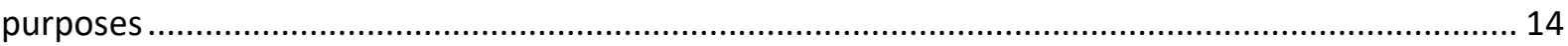

Section S13 Selectivity for silver and gold vs. tantalum related to a removal of tantalum capacitors. 16 Section S14: Tantalum flows and distribution from PCB residues after VIC removal put-on-market and collected in Germany and worldwide in 2013 .......................................................................... 17

Section S15: Tantalum flows and distribution from PCB with VIC put-on-market and collected in

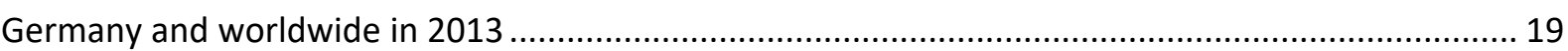

Section S16: Comparison of tantalum contribution from tantalum capacitors and PCB residues ....... 21

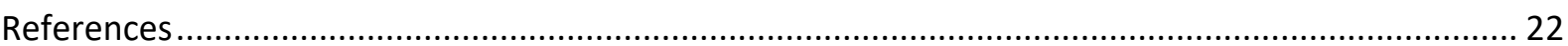


Section S1: Design of a typical tantalum capacitor

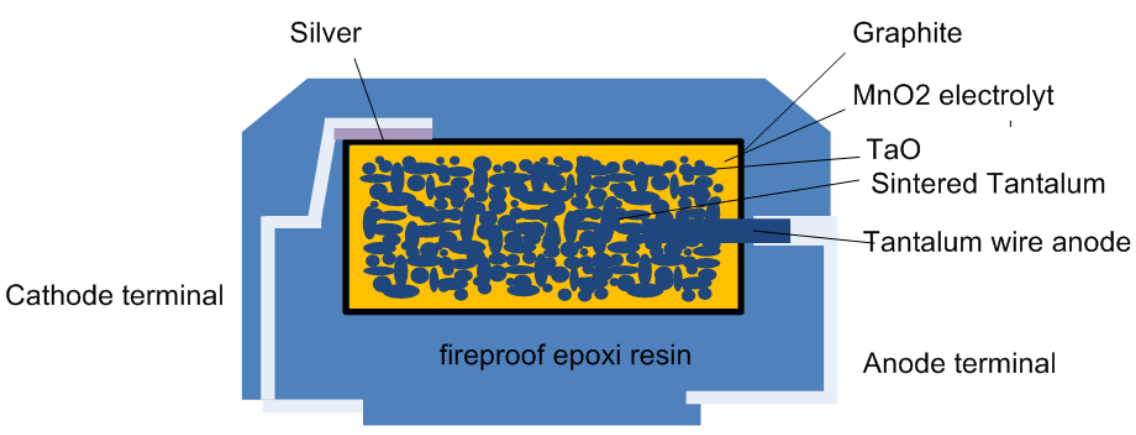

Figure S1: Design of a typical tantalum capacitor (Chancerel et al. 2013)

Section S2: Example pictures of Tantalum capacitors

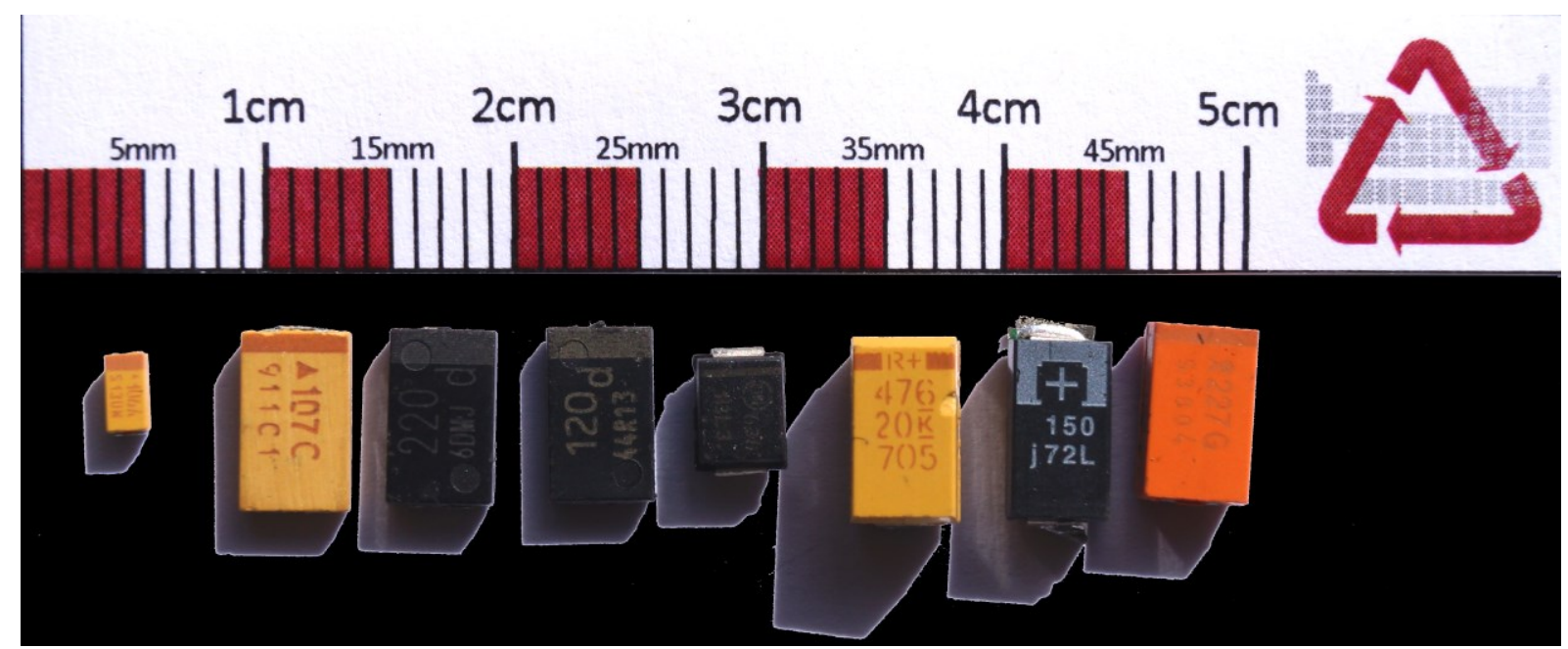

Figure S2: Example pictures of Tantalum capacitors (typical length of $2 \mathrm{~mm}$ to $7 \mathrm{~mm}$ ) 


\section{Section S3: Tantalum shipments and price development between}

\section{2 and 2012}

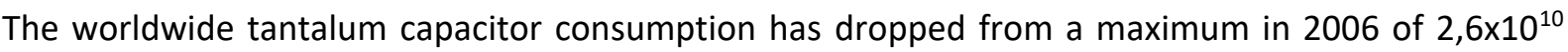
units to $1,4 \times 10^{10}$ units in 2012 (Schwela 2010). Different estimations of the tantalum content per capacitor have been conducted. Market calculations of the tantalum content in capacitors by the Tantalum-Niobium International Study Center (T.I.C.) estimate the Tantalum powder content between 30 and $40 \mathrm{mg} /$ capacitor. (Spitczok von Brisinski et al. 2014) have measured tantalum, manganese, silver, and tin contents in two different types of capacitors via ICP-AES (Inductively coupled plasma atomic emission spectroscopy) analyses. The determined tantalum content varies from about 45 mass$\%$ in surface-mounted device capacitors to about 15 mass-\% in through-hole capacitors.

Figure S3 shows the global shipments for tantalum as raw material for various applications. The indicated price applies for the tantalum content in the raw materials only. Current price from 2015: 236,91 \$/kg (USGS 2016a, 2016b; infoMine 2016)

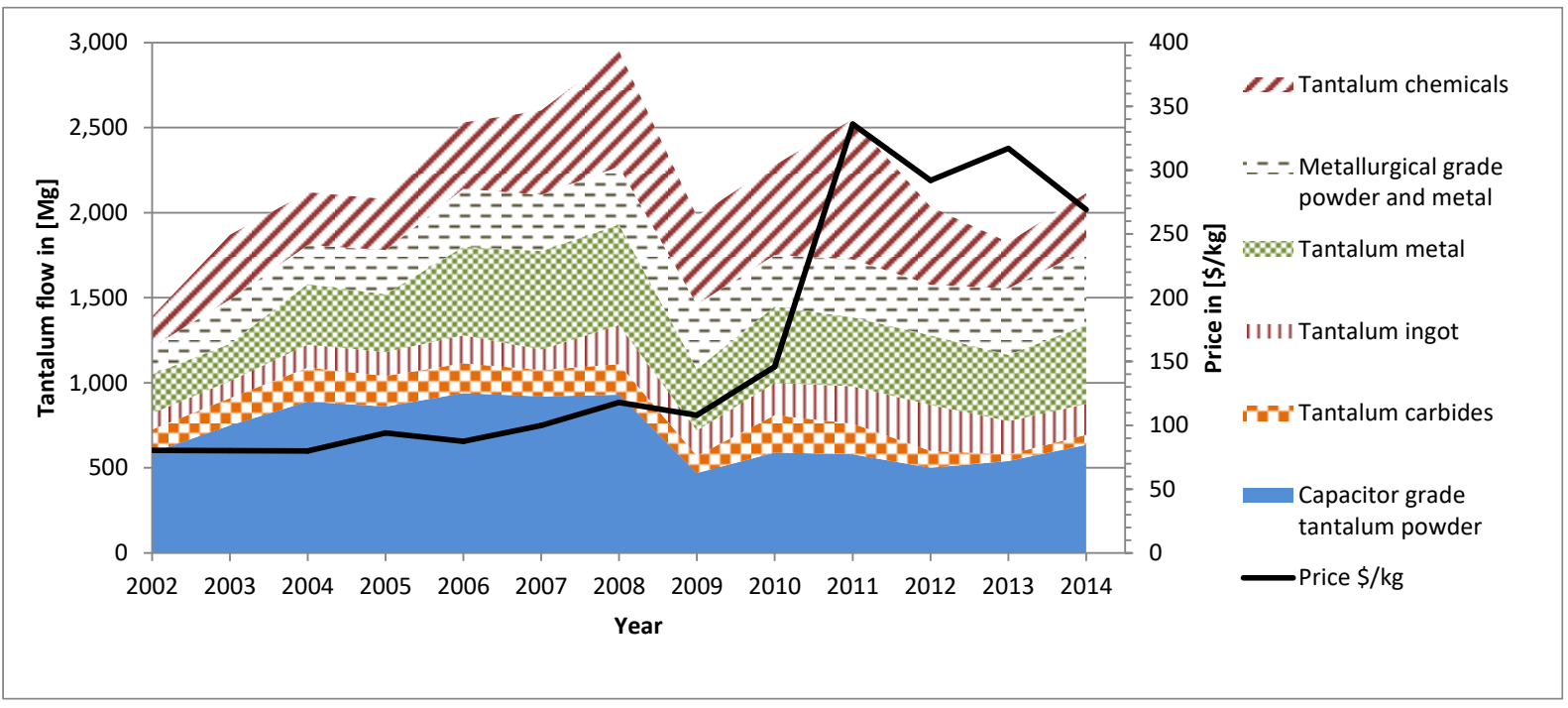

Figure S3: Tantalum shipments and price development between 2002 and 2012 (based on: (Schwela 2010; Buckingham et al. 2014; Tantalum-Niobium International Study Center 2013a, 2013b, 2011, 2016; USGS 2016a; infoMine 2016), Price conversion based on: (USGS 2016b)) 


\section{Section S4: Barrier analysis for the recycling of a target material}

Table S4: Basis elements for a barrier analysis to be investigated

\begin{tabular}{|c|c|c|c|c|c|c|c|}
\hline \multirow[b]{2}{*}{ 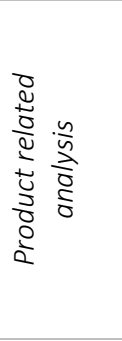 } & \multicolumn{3}{|c|}{ Product design } & \multicolumn{4}{|c|}{ Material composition } \\
\hline & $\begin{array}{l}\text { Change in } \\
\text { product } \\
\text { design }\end{array}$ & $\begin{array}{c}\text { Available } \\
\text { product } \\
\text { information or } \\
\text { labeling }\end{array}$ & $\begin{array}{l}\text { Dissipation } \\
\text { through } \\
\text { product } \\
\text { design }\end{array}$ & $\begin{array}{c}\text { Recycling } \\
\text { conflict with } \\
\text { other } \\
\text { valuable or } \\
\text { relevant } \\
\text { materials }\end{array}$ & $\begin{array}{r}\text { Comp } \\
\mathrm{m} \\
\text { com }\end{array}$ & $\begin{array}{l}\text { ity of } \\
\text { ial } \\
\text { ition }\end{array}$ & $\begin{array}{c}\text { Recycling } \\
\text { conflicts with } \\
\text { contaminants }\end{array}$ \\
\hline \multirow{4}{*}{ 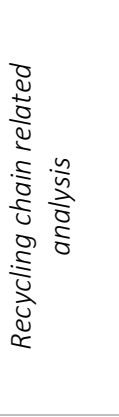 } & \multicolumn{7}{|c|}{ Collection of end-of-life devices } \\
\hline & \multicolumn{3}{|c|}{ Collection rates of relevant devices } & \multicolumn{4}{|c|}{ Trends on collection rates } \\
\hline & \multicolumn{3}{|c|}{ Pre-processing } & \multicolumn{4}{|c|}{ End-processing } \\
\hline & $\begin{array}{l}\text { Mechanical } \\
\text { liberation of } \\
\text { target } \\
\text { materials }\end{array}$ & $\begin{array}{l}\text { Availability of } \\
\text { identification } \\
\text { and sorting } \\
\text { technology }\end{array}$ & $\begin{array}{c}\text { Complexity of } \\
\text { metallurgical } \\
\text { liberation }\end{array}$ & $\begin{array}{r}\text { Separability } \\
\text { liberatic }\end{array}$ & after & End-1 & $\begin{array}{l}\text { fining channels } \\
\text { available }\end{array}$ \\
\hline \multirow{2}{*}{ 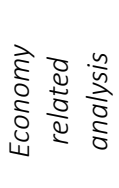 } & \multicolumn{7}{|c|}{ Economy } \\
\hline & \multicolumn{3}{|c|}{$\begin{array}{l}\text { Financial drivers for the recovery of target } \\
\text { material }\end{array}$} & \multicolumn{4}{|c|}{$\begin{array}{l}\text { Energy consumption and waste water/residues } \\
\text { production }\end{array}$} \\
\hline
\end{tabular}




\section{Section S5: Overview of investigated devices and subunits with}

production years 1993-2014

The investigated devices were classified according to the international standardized Harmonized Commodity Description and Coding System, shortly known as the Harmonized System (HS) of the World Customs Organization. For a better categorization, the UNU-Keys, developed by the United Nations Universities, Institute for the Advanced Study of Sustainability, were added (Baldé et al. 2015).

Table S5: Overview of investigated devices and subunits with production years 1993-2014

\begin{tabular}{|c|c|c|c|c|c|c|c|c|c|c|}
\hline & & & & Note & ook & & Desktop I & & & \\
\hline & Phone & phone & Tabiet & $\begin{array}{l}\text { Main } \\
P C B\end{array}$ & $\begin{array}{l}\text { Sec. } \\
P C B\end{array}$ & $H D D$ & $\begin{array}{l}\text { Main } \\
P C B\end{array}$ & $\begin{array}{l}\text { Graphic } \\
\text { Card }\end{array}$ & $\begin{array}{l}\text { Screen } \\
\text { Monitor }\end{array}$ & Server \\
\hline $\begin{array}{l}\text { UNU key } \\
\text { (Parental } \\
\text { device) }\end{array}$ & 0306-01 & 0306-02 & $303-02$ & 0303 & 0303 & 0301 & 0302 & 0302 & 0309 & 0307 \\
\hline $\begin{array}{l}\text { HS key } \\
\text { (Parental } \\
\text { device) }\end{array}$ & 851712 & 851712 & 847130 & 847130 & 847130 & 847170 & 847141 & 847141 & 852851 & 847149 \\
\hline $\begin{array}{l}\text { Number of } \\
\text { devices } \\
\text { disassembled } \\
\text { in total }\end{array}$ & 59 & 26 & 16 & 63 & 128 & 99 & 90 & 56 & 70 & 14 \\
\hline $\begin{array}{l}\text { Production } \\
\text { years }\end{array}$ & $\begin{array}{l}1998- \\
2011\end{array}$ & $\begin{array}{l}2007- \\
2014\end{array}$ & $\begin{array}{l}2010- \\
2015\end{array}$ & 1993 & 2010 & $\begin{array}{l}1998- \\
2008\end{array}$ & $\begin{array}{l}1996- \\
2010\end{array}$ & $\begin{array}{l}1995- \\
2012\end{array}$ & no dat & vailable \\
\hline
\end{tabular}

Note: Mobile phones comprise phones without touch screens; smartphones with touch screens. The PCB obtained from notebooks were classified into main $P C B$, containing the central processing unit ( $C P U)$, and secondary $P C B$, comprising all other contained $P C B$ (on average a ratio of $1: 1.1$ (primary : secondary) PCB was found). Hard disk drives (HDD) comprise storage devices used in household applications covering both internal and external devices, but excluding solid state drives

\section{Section S6: Overview on sample sizes and laboratories for chemical} analyses

Table S6: Chemically analyzed printed circuit boards (PCB) and visually identifiable tantalum capacitors (VIC)

\begin{tabular}{|c|c|c|c|c|c|c|c|c|c|}
\hline Sample & $\begin{array}{l}\text { Mobile } \\
\text { phone }\end{array}$ & Smartphone & Tablet & Laptop & $\begin{array}{c}\text { Desktop } \\
\text { PC }\end{array}$ & HDD & TFT & Server & VIC \\
\hline UNU key & 0306-01 & $0306-02$ & $303-02$ & 0303 & 0302 & 0301 & 0309 & 0307 & - \\
\hline $\begin{array}{c}\text { Total } \\
\text { sample } \\
\text { mass }[\mathrm{kg}]\end{array}$ & 1 & 0.5 & 0.6 & 18.7 & 10.4 & 1.5 & 9.7 & 3.8 & 0.4 \\
\hline $\begin{array}{l}\text { Number of } \\
\text { units } \\
\text { analyzed } \\
\text { chemically }\end{array}$ & 47 & 26 & 16 & 57 & 16 & 46 & 70 & 6 & 3142 \\
\hline Laboratory & 1 & 2 & 2 & 1 & 1 & 1 & 1 & 1 & 1 \\
\hline
\end{tabular}




\section{Section S7: Sub-levels for the calculation of the tantalum masses based on relevant devices POM and collected for recycling purposes}

Table S7: Sub-levels for the calculation of the tantalum masses put on market (POM) and end of life (EOL)

\begin{tabular}{|c|c|c|c|c|c|c|}
\hline \multicolumn{7}{|c|}{ Put-on-market } \\
\hline Sub-levels of calculation & $\begin{array}{l}\text { Number } \\
\text { equipment } \\
\text { put-on- } \\
\text { market } \\
\text { [pieces] }\end{array}$ & $\begin{array}{c}\text { Mass } \\
\text { equipment } \\
\text { put-on- } \\
\text { market } \\
{[\mathrm{Mg}]}\end{array}$ & $\begin{array}{l}\text { Masses } \\
\text { printed } \\
\text { circuit } \\
\text { boards } \\
\text { POM [Mg] }\end{array}$ & $\begin{array}{c}\text { Tantalum } \\
\text { capacitor } \\
\text { mass POM } \\
\text { [Mg] }\end{array}$ & $\begin{array}{l}\text { Tantalum } \\
\text { mass } \\
\text { POM } \\
\text { through } \\
\text { VIC }[\mathrm{Mg}]\end{array}$ & $\begin{array}{c}\text { Tantalum } \\
\text { mass } \\
\text { POM } \\
\text { through } \\
\text { PCB [Mg] }\end{array}$ \\
\hline Needed information & $\begin{array}{l}\text { Market } \\
\text { data from } \\
\text { literature } \\
\text { research }\end{array}$ & $\begin{array}{c}\text { Disassembly } \\
\text { trials }\end{array}$ & $\begin{array}{c}\text { Disassembly } \\
\text { trials }\end{array}$ & $\begin{array}{c}\text { Disassembly } \\
\text { trials }\end{array}$ & $\begin{array}{l}\text { Chemical } \\
\text { analyses } \\
\text { of } \\
\text { capacitors }\end{array}$ & $\begin{array}{c}\text { Chemical } \\
\text { analyses } \\
\text { of PCB }\end{array}$ \\
\hline \multicolumn{7}{|c|}{ Collected for recycling purposes } \\
\hline Sub-levels of calculation & $\begin{array}{c}\text { Masses } \\
\text { equipment } \\
\text { collected } \\
\text { for } \\
\text { recycling } \\
\text { purposes } \\
\text { [Mg] }\end{array}$ & $\begin{array}{c}\text { Number } \\
\text { equipment } \\
\text { collected } \\
\text { for } \\
\text { recycling } \\
\text { purposes } \\
\text { [pieces] }\end{array}$ & $\begin{array}{c}\text { Masses } \\
\text { collected } \\
\text { printed } \\
\text { circuit } \\
\text { boards [Mg] }\end{array}$ & $\begin{array}{l}\text { Tantalum } \\
\text { capacitor } \\
\text { mass } \\
\text { collected } \\
{[\mathrm{Mg}]}\end{array}$ & $\begin{array}{l}\text { Tantalum } \\
\text { mass } \\
\text { collected } \\
\text { through } \\
\text { VIC }[\mathrm{Mg}]\end{array}$ & $\begin{array}{c}\text { Tantalum } \\
\text { mass } \\
\text { collected } \\
\text { through } \\
\text { PCB [Mg] }\end{array}$ \\
\hline Needed information & $\begin{array}{c}\text { Disassembly } \\
\text { trials }\end{array}$ & $\begin{array}{l}\text { Collection } \\
\text { data from } \\
\text { literature } \\
\text { research } \\
\text { and own } \\
\text { studies }\end{array}$ & $\begin{array}{c}\text { Disassembly } \\
\text { trials }\end{array}$ & $\begin{array}{c}\text { Disassembly } \\
\text { trials }\end{array}$ & $\begin{array}{l}\text { Chemical } \\
\text { analyses } \\
\text { of } \\
\text { capacitors }\end{array}$ & $\begin{array}{c}\text { Chemical } \\
\text { analyses } \\
\text { of PCB }\end{array}$ \\
\hline
\end{tabular}

Based on: own studies and (Cemix 2013; Statista 2015a, 2015b; Stiftung elektro-altgeräte register 2015) 


\section{Section S8: PCB and VIC content}
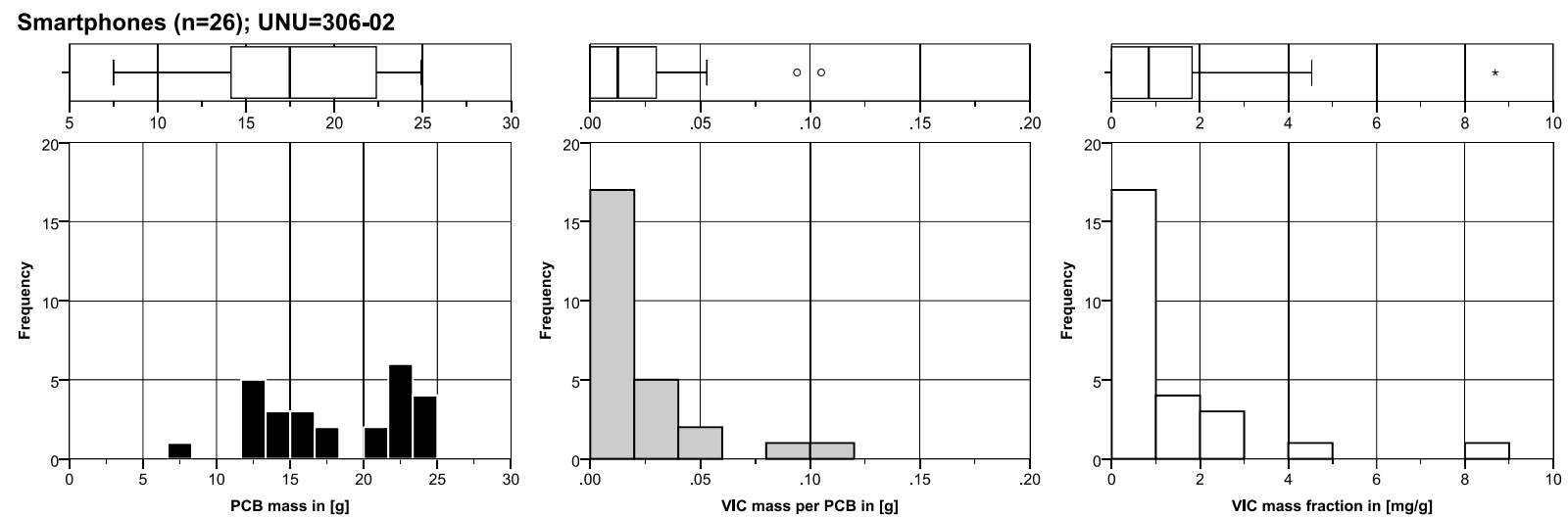

Figure 58-1: Printed circuit board (PCB) mass per device (left), visually identifiable tantalum capacitors (VIC) per device (middle) and VIC mass fraction per PCB (right) for smartphones. With interquartile range (25/75 \%); whiskers 1.5 IQR; asterisk = extremum; circle $=$ outlier .

Tablets $(n=16) ;$ UNU=306-02
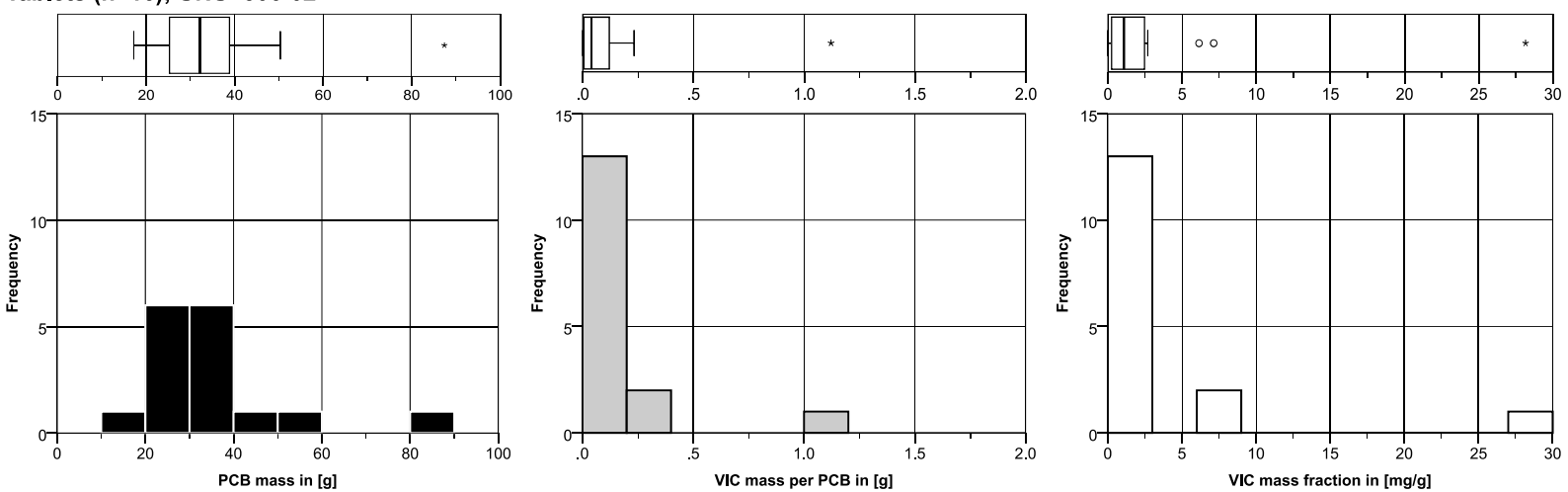

Figure S8-2: Printed circuit board (PCB) mass per device (left), visually identifiable tantalum capacitors (VIC) per device (middle) and VIC mass fraction per PCB (right) for tablets. With interquartile range (25/75\%); whiskers 1.5 IQR; asterisk = extremum; circle = outlier

Notebooks secondary PCB $(n=128) ;$ UNU=303
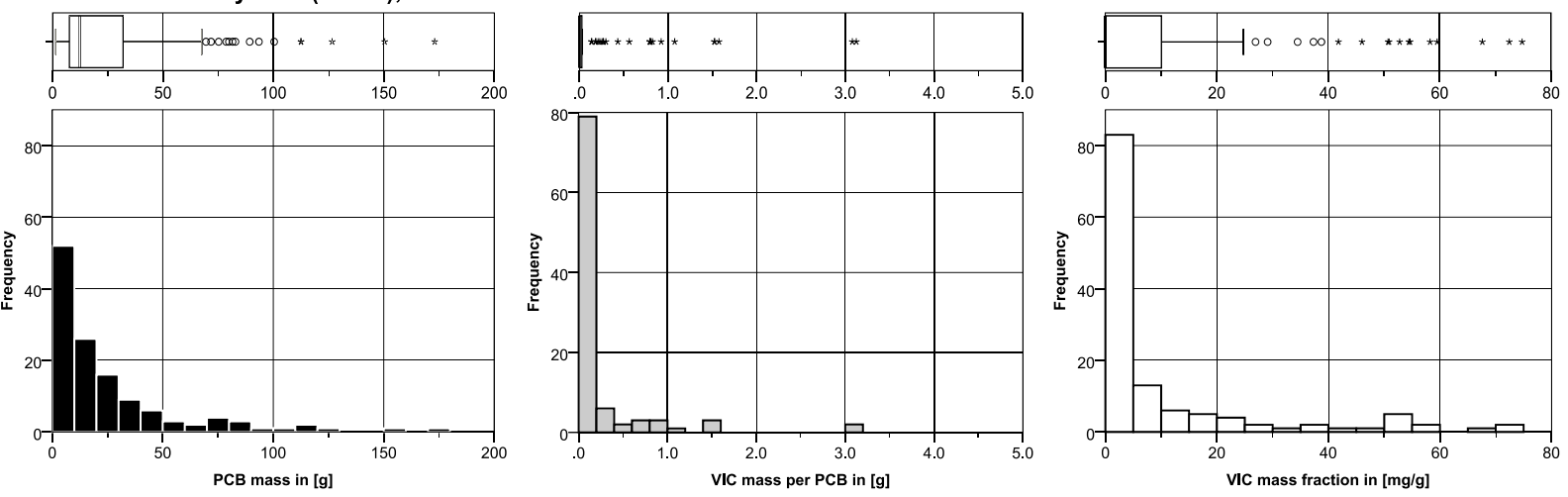

Figure 58-3: Printed circuit board (PCB) mass per device (left), visually identifiable tantalum capacitors (VIC) per device (middle) and VIC mass fraction per PCB (right) for the secondary PCB from notebooks. With interquartile range (25/75 \%); whiskers 1.5 IQR; asterisk = extremum; circle = outlier. 

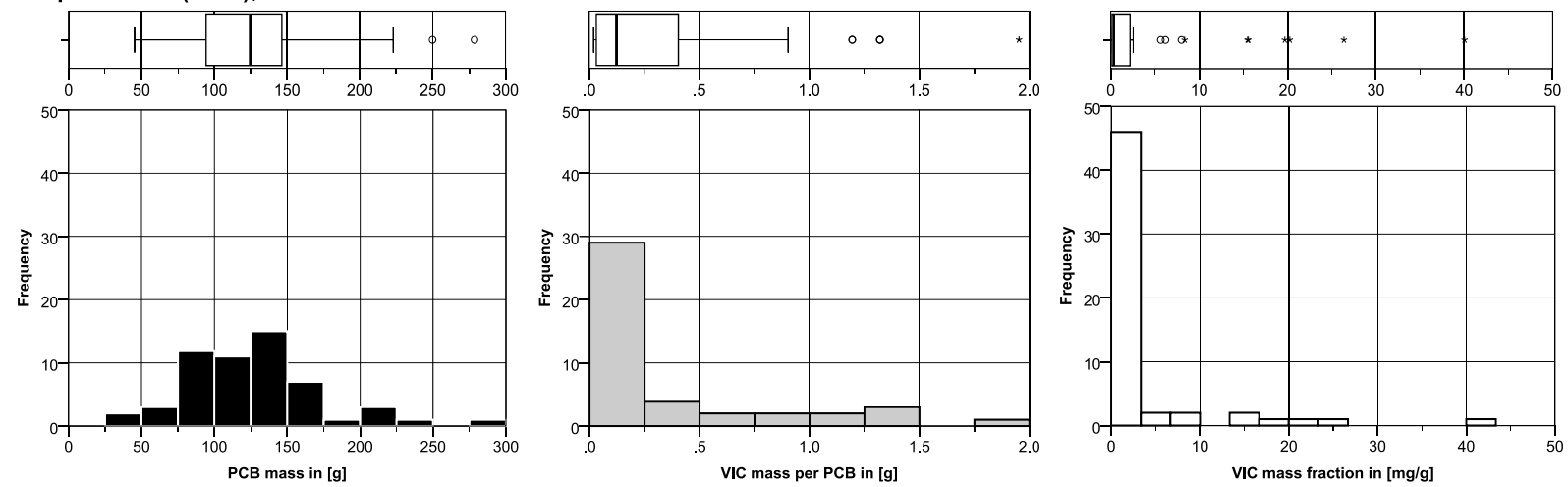

Figure 58-4: Printed circuit board (PCB) mass per device (left), visually identifiable tantalum capacitors (VIC) per device (middle) and VIC mass fraction per PCB (right) for graphic cards. With interquartile range (25/75 \%); whiskers 1.5 IQR; asterisk = extremum; circle $=$ outlier

\section{Hard disk drives 3.5" (n=99); UNU=301}
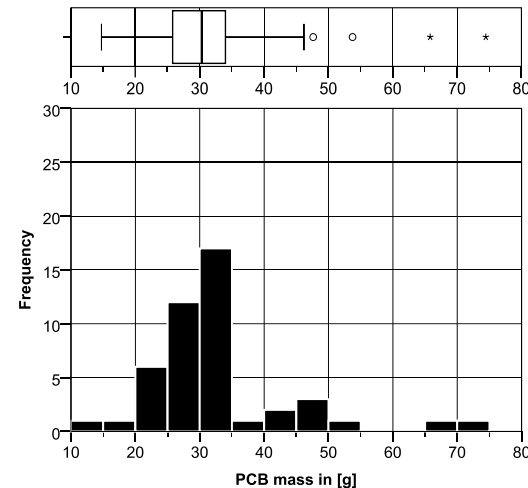
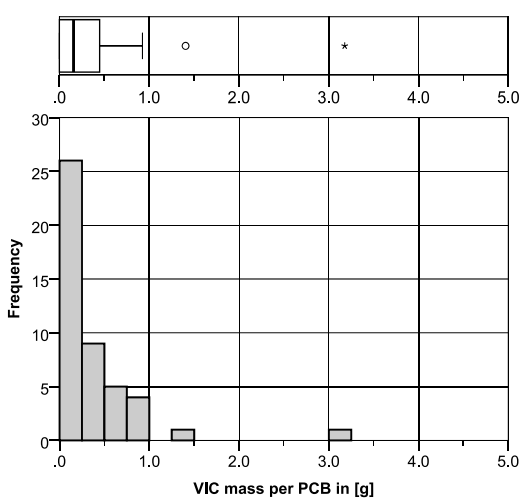
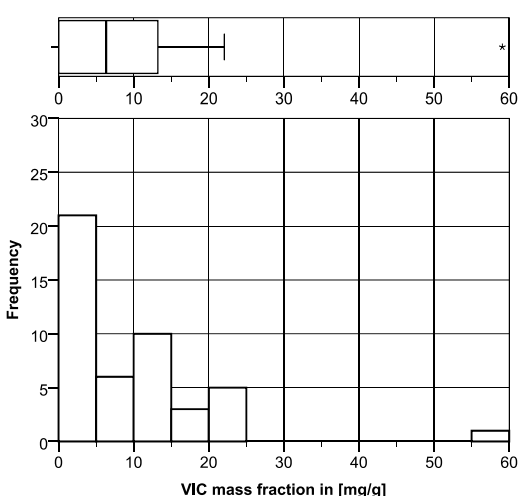

Figure S8-5: Printed circuit board (PCB) mass per device (left), visually identifiable tantalum capacitors (VIC) per device (middle) and VIC mass fraction per PCB (right) for hard disk drives. With interquartile range (25/75 \%); whiskers 1.5 IQR; asterisk = extremum; circle = outlier.

Mainboard from desktop PC $(n=90)$; UNU=302
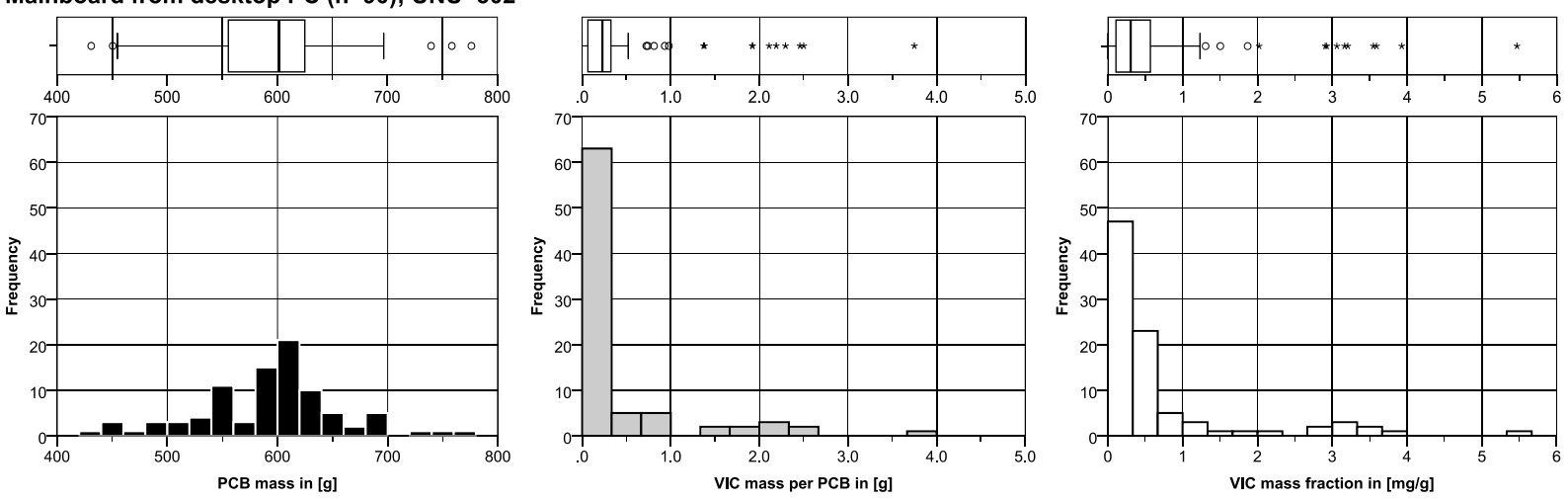

Figure 58-6: Printed circuit board (PCB) mass per device (left), visually identifiable tantalum capacitors (VIC) per device (middle) and VIC mass fraction per PCB (right) for desktop PC. With interquartile range (25/75\%); whiskers 1.5 IQR; asterisk = extremum; circle = outlier . 
Server mainboard $(n=14) ; \mathrm{UNU}=307$
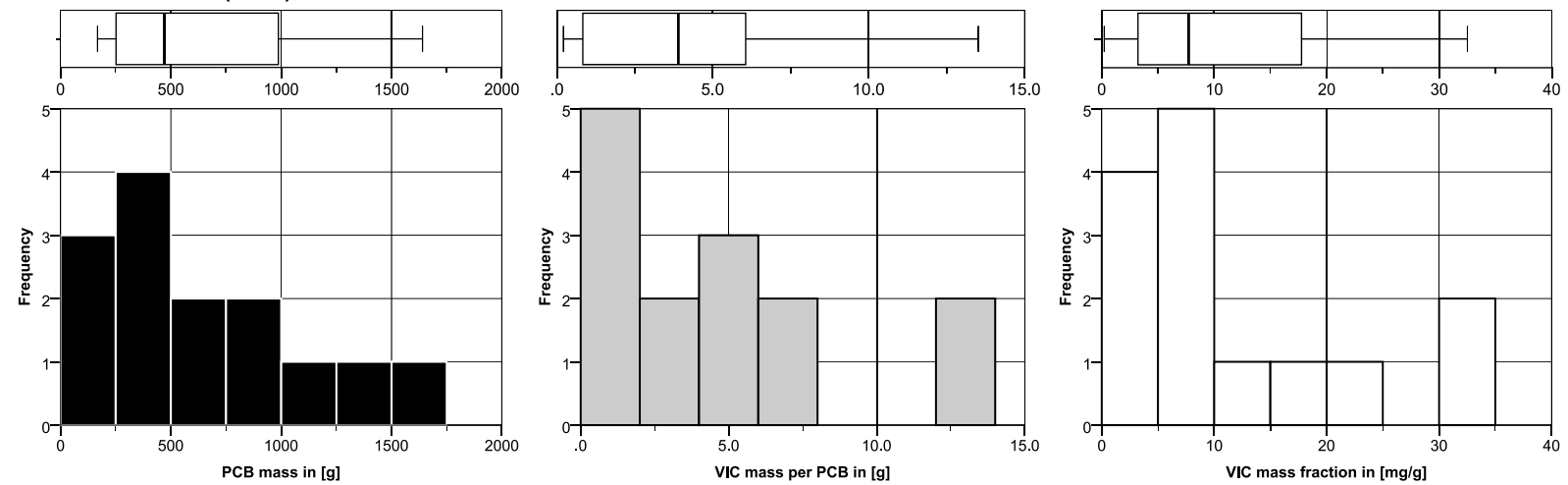

Figure 58-7: Printed circuit board (PCB) mass per device (left), visually identifiable tantalum capacitors (VIC) per device (middle) and VIC mass fraction per PCB (right) for server. With interquartile range (25/75\%); whiskers 1.5 IQR; asterisk= extremum; circle = outlier.

\section{Flat screen monitor $(n=70) ; \mathrm{UNU}=309$}
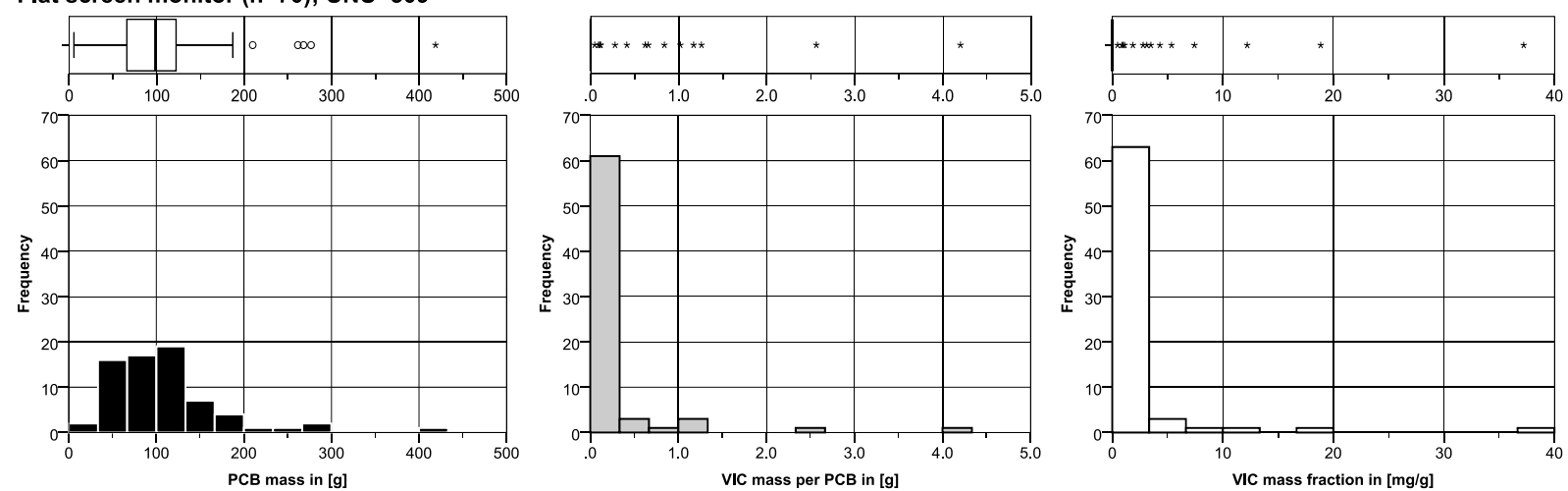

Figure S8-8: Printed circuit board (PCB) mass per device (left), visually identifiable tantalum capacitors (VIC) per device

(middle) and VIC mass fraction per PCB (right) for flat screen monitors. With interquartile range (25/75 \%); whiskers 1.5 IQR; asterisk = extremum; circle $=$ outlier . 
Section 59 Identifiable tantalum capacitors per unit

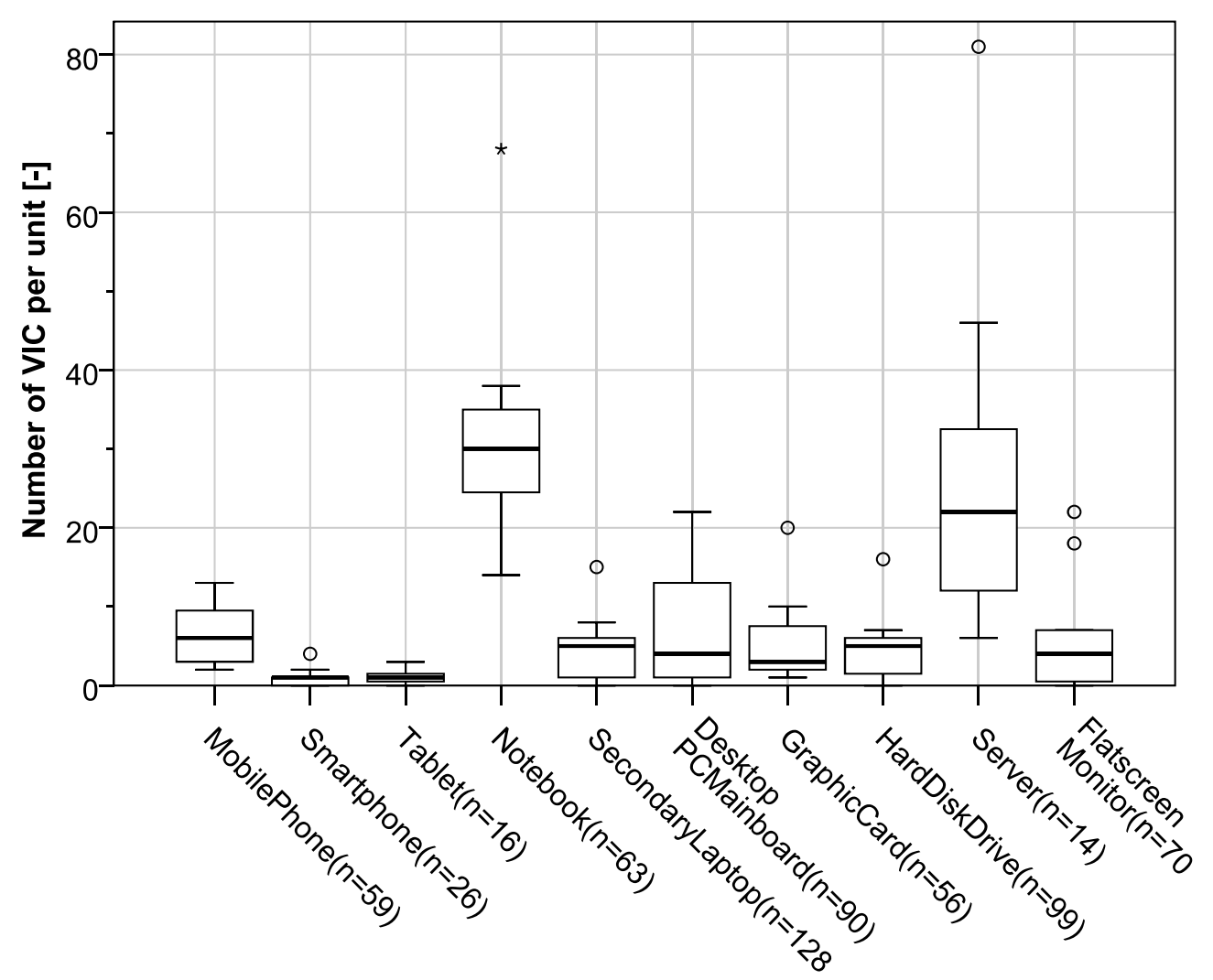

Figure S9: Number of visually identifiable tantalum capacitors (VIC) per unit, depicted as boxplots with interquartile range (25/75\%), whiskers 1.5 IQR, asterisk = extremum, circle $=$ outlier . 


\section{Section S10: Elemental composition of visual identifiable tantalum}

\section{capacitors}

Table S10: Chemical composition of analyzed visually identifiable tantalum capacitors (VIC) from investigated equipment types

\begin{tabular}{|c|c|c|}
\hline \multirow{2}{*}{ ppm } & \multicolumn{2}{|c|}{ Tantalum capacitors from selected PCB's } \\
\hline & Average & StDev \\
\hline $\mathrm{Ag}$ & 32,066 & 417 \\
\hline $\mathrm{Au}$ & 15 & 0 \\
\hline $\mathrm{Pt}$ & $<2$ & \\
\hline $\mathrm{Pd}$ & 61 & 2 \\
\hline $\mathrm{Pb}$ & 1327 & 133 \\
\hline $\mathrm{Cu}$ & 38,630 & 1,159 \\
\hline $\mathrm{Bi}$ & 1 & 0 \\
\hline $\mathrm{Ni}$ & 21,720 & 652 \\
\hline Co & $<0.0525$ & \\
\hline As & $<0.0525$ & \\
\hline Sb & 5,316 & 532 \\
\hline Sn & 6,981 & 698 \\
\hline $\mathrm{Zn}$ & 2,854 & 285 \\
\hline $\mathrm{Fe}$ & 38,050 & 1,142 \\
\hline $\mathrm{Te}$ & $<0.0525$ & \\
\hline $\mathrm{Cd}$ & $<0.0525$ & \\
\hline $\mathrm{Mn}$ & 31,860 & 956 \\
\hline Ge & $<0.1$ & \\
\hline $\mathrm{Mg}$ & 5,381 & 269 \\
\hline Al & 21,122 & 1,056 \\
\hline $\mathrm{Ca}$ & 2,389 & 119 \\
\hline $\mathrm{Si}$ & 156,310 & 7,816 \\
\hline Ba & 1,397 & 70 \\
\hline $\mathrm{Ti}$ & 630 & 31 \\
\hline $\mathrm{Ta}$ & 484,500 & 4,845 \\
\hline $\mathrm{Be}$ & $<0.00105$ & \\
\hline Ga & $<0.1$ & \\
\hline $\mathrm{Zr}$ & $<0.1051$ & \\
\hline La & $<0.2239$ & \\
\hline $\mathrm{Ce}$ & $<0.0856$ & \\
\hline $\mathrm{Pr}$ & $<0.0525$ & \\
\hline $\mathrm{Nd}$ & $<0.0525$ & \\
\hline Eu & $<0.26$ & \\
\hline $\mathrm{Tb}$ & $<0.0525$ & \\
\hline Dy & $<0.525$ & \\
\hline $\mathrm{Sm}$ & $<0.0525$ & \\
\hline LOI & & \\
\hline
\end{tabular}




\section{Section S11: PCB residue composition}

Table S11: Chemical composition of analyzed residual printed circuit boards (PCB) without visually identifiable tantalum capacitors (VIC)

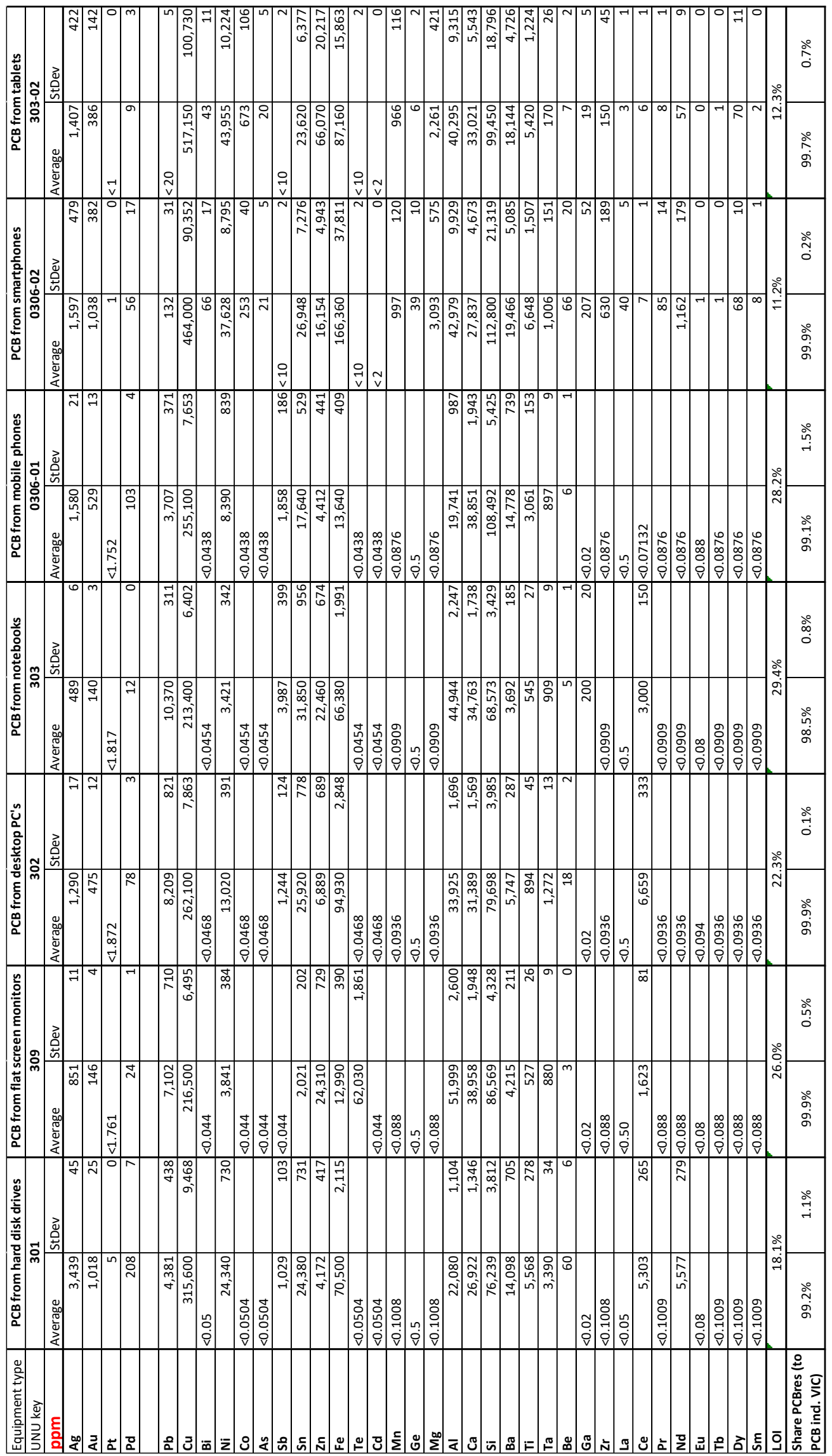


Section S12: Detailed calculation of Tantalum in devices POM and devices collected for recycling purposes

Table S12-1: Tantalum potential calculation for mobile phones, smartphones, tablets, notebooks, desktop PCs and servers

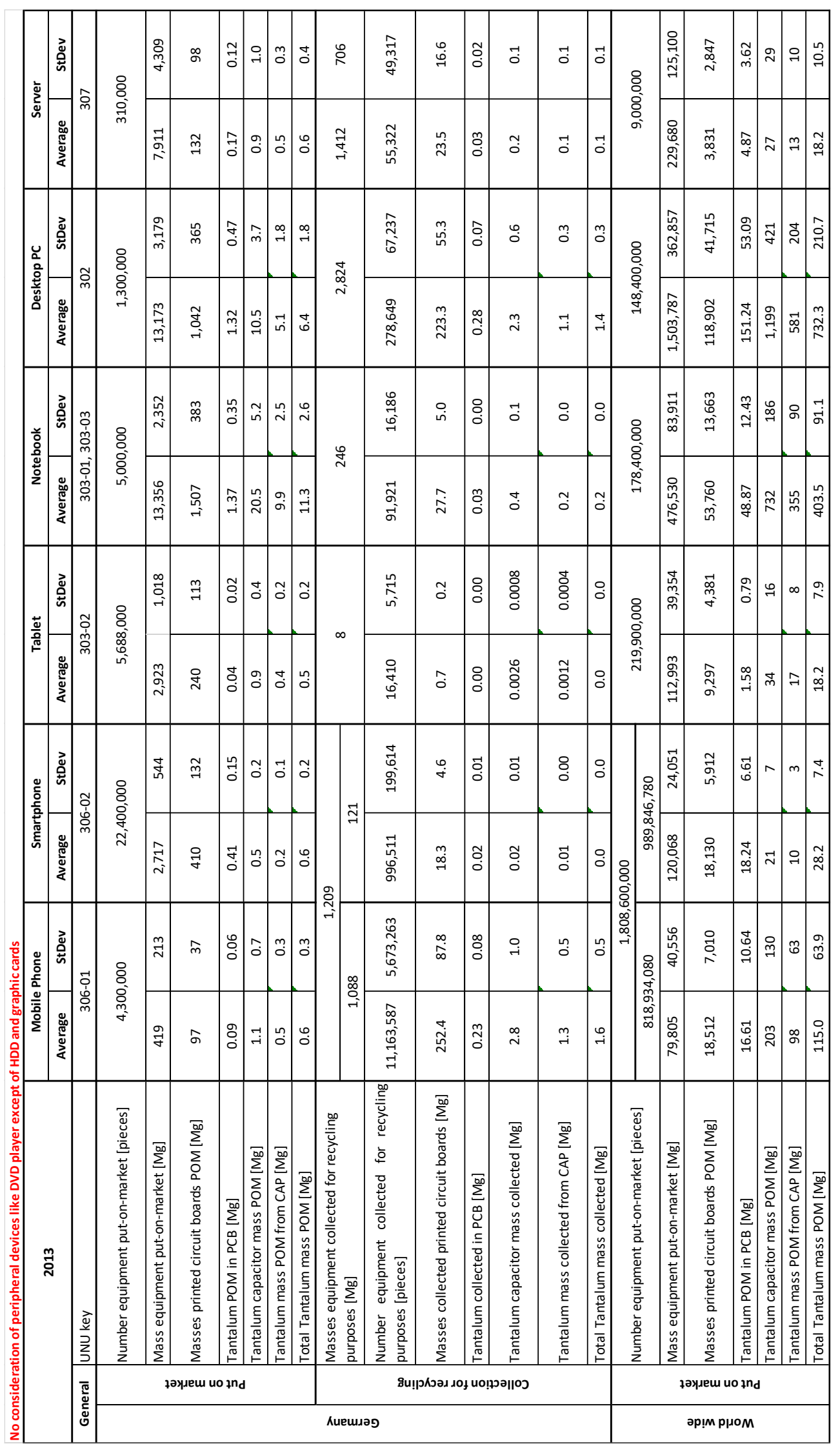


Table S12-2: Tantalum potential calculation for flat screen monitors, graphic cards, hard disk drives (HDD) from notebooks, desktop PCs, servers and HDDs with various origins

\begin{tabular}{|c|c|c|c|c|c|c|c|c|c|c|c|c|c|c|c|c|c|c|c|c|}
\hline \multirow{2}{*}{ 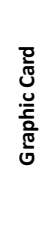 } & \multirow{2}{*}{ 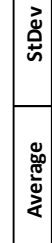 } & \multirow{2}{*}{$\begin{array}{l}\stackrel{8}{0} \\
\text { o. } \\
\text { N }\end{array}$} & \multicolumn{2}{|r|}{$\stackrel{m}{m}$} & & $\stackrel{\circ}{\circ}$ & & & & & & \multirow{2}{*}{$\begin{array}{l}8 \\
8 \\
0 \\
0 \\
0 \\
n \\
1\end{array}$} & \multicolumn{2}{|c|}{0} & & \multirow{2}{*}{\multicolumn{2}{|c|}{ 大 }} \\
\hline & & & & in & & $\begin{array}{l}-1 \\
0\end{array}$ & & $\stackrel{m}{q}$ & 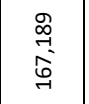 & 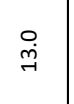 & & : & $\stackrel{\circ}{0}$ & & & & 忽 & & & \\
\hline \multirow{2}{*}{ 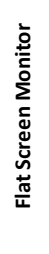 } & 㤐 & \multirow{2}{*}{$\begin{array}{l}8 \\
: \\
\text { : } \\
\text { i }\end{array}$} & $\hat{\mathcal{F}}$ & $\stackrel{\text { లి }}{\text { D. }}$ & 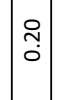 & : & $\begin{array}{cc}0 \\
0 \\
0\end{array}$ & \multirow{2}{*}{$\underset{\mathrm{f}}{\mathrm{f}}$} & $\underset{\infty}{\overrightarrow{7}}$ & $\stackrel{m}{d}$ & $\mid \begin{array}{l}0 \\
0 \\
0\end{array}$ & : & $\stackrel{\circ}{\circ}$ & $\mid \stackrel{0}{0}$ & \multirow{2}{*}{$\begin{array}{l}8 \\
8 \\
0 \\
0 \\
i . \\
0\end{array}$} & 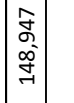 & 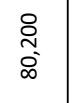 & \begin{tabular}{l|l}
$\stackrel{\leftrightarrow}{\leftrightarrow}$ \\
$\stackrel{R}{R}$ & $\vec{f}$
\end{tabular} & $\infty$ & \begin{tabular}{|c}
$\infty$ \\
$\infty$ \\
$\infty$
\end{tabular} \\
\hline & 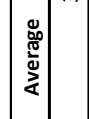 & & $\left|\begin{array}{l}0 \\
0 \\
0 \\
0 \\
-1\end{array}\right|$ & \& & $\mid \begin{array}{l}7 \\
0 \\
0\end{array}$ & \begin{tabular}{|l|l}
$\infty$ \\
$\vdots$ \\
\hdashline
\end{tabular} & \begin{tabular}{l}
$\infty$ \\
$\dot{b}$ \\
\hdashline
\end{tabular} & & $\begin{array}{l}\text { ô } \\
\stackrel{y}{\text { İ }}\end{array}$ & $\begin{array}{l}\infty \\
\dot{q}\end{array}$ & $\mid$\begin{tabular}{l|} 
\\
0 \\
0
\end{tabular} & $\overrightarrow{0}$ & : & - & & $\left|\begin{array}{l}m \\
0 \\
\tilde{n} \\
n \\
n \\
m\end{array}\right|$ & 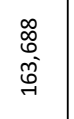 & 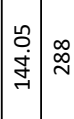 & & $\left|\begin{array}{c}a \\
\infty \\
\infty \\
\sim\end{array}\right|$ \\
\hline \multirow{2}{*}{ 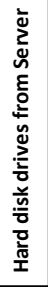 } & \multirow{2}{*}{ 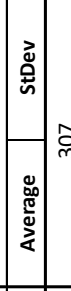 } & 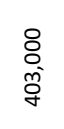 & 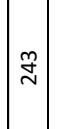 & $\vec{N}$ & $\mid \begin{array}{l}0 \\
0 \\
0\end{array}$ & \begin{tabular}{l|l}
$\tilde{o}$ & $\overline{0}$ \\
0
\end{tabular} & $\begin{aligned} 7 \\
5\end{aligned}$ & $F$ & 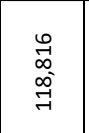 & $\stackrel{m}{m}$ & $\mid \begin{array}{l}0 \\
0 \\
0\end{array}$ & $\stackrel{8}{\circ}$ & $\stackrel{\circ}{\circ}$ & $\stackrel{\circ}{\circ}$ & $\begin{array}{l}8 \\
8 \\
0 \\
0 \\
7 \\
7\end{array}$ & 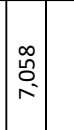 & $\hat{o}$ & $\begin{array}{lll}\stackrel{8}{0} \\
\stackrel{1}{*}\end{array}$ & $m$ & $\left.\mid \begin{array}{l}: \\
\dot{m}\end{array}\right]$ \\
\hline & & 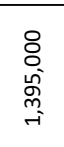 & 员 & 乌 & $\mid \begin{array}{l}\stackrel{n}{0} \\
0\end{array}$ & \begin{tabular}{|l|c}
$n$ \\
$\vdots$
\end{tabular} & $\begin{array}{lll} \\
\end{array}$ & $\stackrel{M}{\exists}$ & $\begin{array}{l}: \\
: \\
\text { o. } \\
\text { ల. }\end{array}$ & $\stackrel{m}{\stackrel{n}{a}}$ & $\mid \begin{array}{l}0 \\
0 \\
0\end{array}$ & $\overrightarrow{0}$ & $\overrightarrow{0}$ & $\overrightarrow{0}$ & 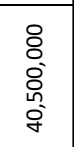 & $\mid$\begin{tabular}{|}
$\mid$ \\
0 \\
$a$ \\
$\vec{i}$
\end{tabular} & 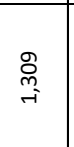 & $\begin{array}{l}\dot{f} \\
\dot{f}\end{array}$ & 6 & \begin{tabular}{|c|}
$\mid \infty$ \\
$\stackrel{9}{9}$
\end{tabular} \\
\hline \multirow{2}{*}{ 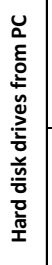 } & \multirow{2}{*}{ 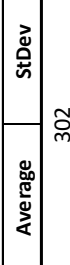 } & \multirow{2}{*}{ 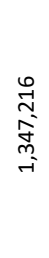 } & \% & $\stackrel{\leftrightarrow}{\neg}$ & $\mid \begin{array}{l}0 \\
0 \\
0\end{array}$ & 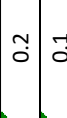 & $\begin{array}{c}-1 \\
0\end{array}$ & 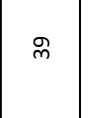 & 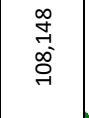 & $\stackrel{m}{m}$ & $\mid \begin{array}{l}\mid \\
0 \\
0\end{array}$ & 8 & $\stackrel{\circ}{\circ}$ & : & \multirow{2}{*}{ 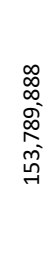 } & 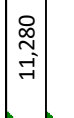 & 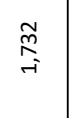 & $\left|\begin{array}{c}\dot{\infty} \\
\dot{\omega}\end{array}\right| \neg$ & & $\mid \begin{array}{c}m \\
\stackrel{n}{9}\end{array}$ \\
\hline & & & $\mid \vec{p}$ & F & $\mid \begin{array}{l}\stackrel{2}{a} \\
0\end{array}$ & \begin{tabular}{|l|l}
$:$ & 0 \\
0
\end{tabular} & $\begin{array}{lll} \\
\end{array}$ & Эे & $\begin{array}{l}\text { Na } \\
\text { 今. } \\
\text { ì }\end{array}$ & $\stackrel{7}{\pi}$ & $\mid \begin{array}{l}0 \\
0 \\
0\end{array}$ & $\overrightarrow{0}$ & $\stackrel{\circ}{0}$ & $\begin{array}{r}-1 \\
0\end{array}$ & & $\mid$\begin{tabular}{l|}
0 \\
0 \\
$\infty$ \\
$\infty$
\end{tabular} & $\begin{array}{l}\stackrel{8}{\alpha} \\
\underset{\gamma}{\sigma}\end{array}$ & 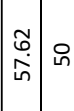 & $\stackrel{\text { p }}{p}$ & $\mid \begin{array}{l}\overrightarrow{1} \\
\vec{\infty}\end{array}$ \\
\hline \multirow{2}{*}{ 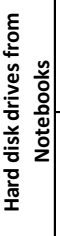 } & \multirow{2}{*}{ 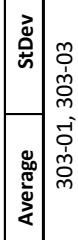 } & \multirow{2}{*}{ 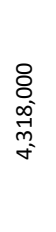 } & nి & r & $\begin{array}{l}0 \\
0 \\
0\end{array}$ & $\because 0$ & 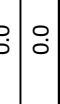 & r & $\begin{array}{l}\stackrel{9}{\circ} \\
\text { के } \\
\text { d }\end{array}$ & g̊ & \begin{tabular}{|l|} 
\\
0 \\
0
\end{tabular} & : & : & 吕 & 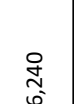 & $\mid$\begin{tabular}{l}
0 \\
0 \\
0 \\
\hdashline \\
-1
\end{tabular} & 岕 & \begin{tabular}{|c|c|c} 
& $m$ \\
0 & $m$
\end{tabular} & 0 & g. \\
\hline & & & 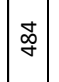 & \&े & \begin{tabular}{c}
$\approx$ \\
\hdashline \\
0
\end{tabular} & $\mid \begin{array}{l}0 \\
0\end{array}$ & $\begin{array}{l}n \\
3\end{array}$ & $\sigma$ & 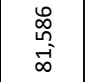 & $\mathcal{F}$ & $\begin{array}{l}0 \\
0 \\
0\end{array}$ & $\stackrel{\circ}{\circ}$ & 茴 & $\stackrel{\circ}{0}$ & $\stackrel{\oplus}{\vec{H}}$ & 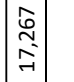 & 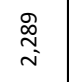 & 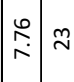 & $F$ & $\mid$\begin{tabular}{l|}
$\infty$ \\
$\infty$ \\
$\rightarrow$
\end{tabular} \\
\hline 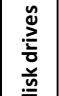 & ڤे̀ & & 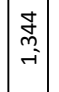 & 苛 & $\begin{array}{c}\stackrel{m}{m} \\
0\end{array}$ & \begin{tabular}{l|l}
\multirow{i}{*}{} & na \\
&
\end{tabular} & $\begin{array}{lll}\overbrace{5} & \bullet \\
\end{array}$ & & $\begin{array}{l}\infty \\
\infty \\
\infty\end{array}$ & $\vec{F}$ & \begin{tabular}{|l|} 
\\
0 \\
0 \\
0
\end{tabular} & ก̃ & $\overrightarrow{0}$ & $\overrightarrow{0}$ & ৪ & 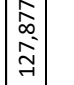 & $\begin{array}{l}\text { 虽 } \\
\text { o. }\end{array}$ & 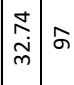 & & $\begin{array}{l}\text { if } \\
\text { in }\end{array}$ \\
\hline 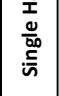 & 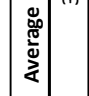 & "in & $\mid \begin{array}{c}\hat{\sigma} \\
\stackrel{\sim}{\mathbf{s}}\end{array}$ & ईे & \begin{tabular}{|l|}
$\vec{b}$ \\
0 \\
0
\end{tabular} & 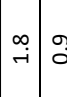 & $\begin{array}{l}g_{0} \\
\end{array}$ & & 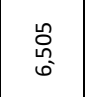 & 啶 & $\begin{array}{l}0 \\
0 \\
0\end{array}$ & $\stackrel{ナ}{\circ}$ & õ & $\stackrel{m}{0}$ & 茼 & 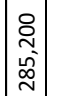 & 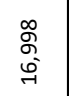 & 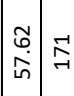 & $\infty$ & $\mid \begin{array}{l}\hat{j} \\
\dot{q}\end{array}$ \\
\hline iे & 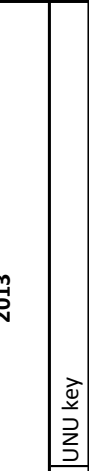 & 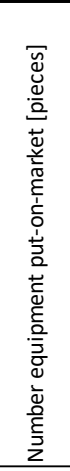 & 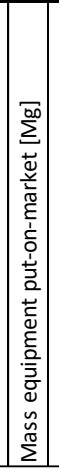 & 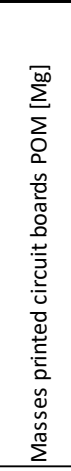 & 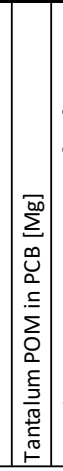 & 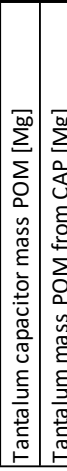 & 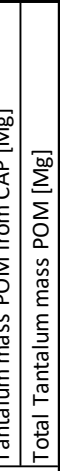 & 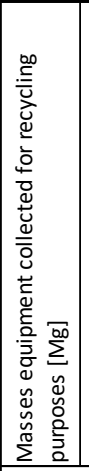 & 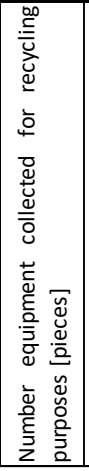 & 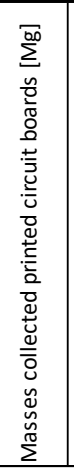 & 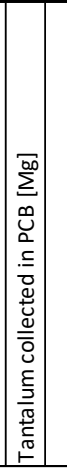 & 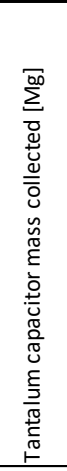 & 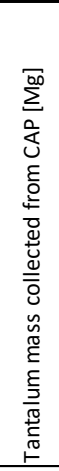 & 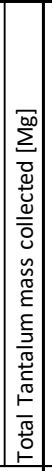 & 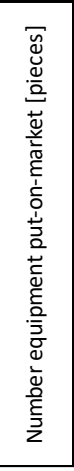 & 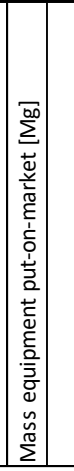 & 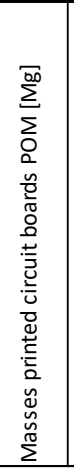 & 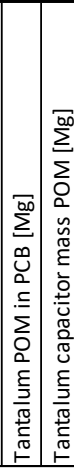 & 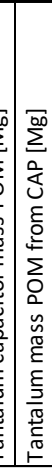 & 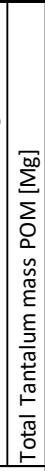 \\
\hline & & & & әудеш и & $10 \mathrm{ind}_{\mathrm{d}}$ & & & & & 109 & 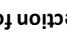 & כסוןכ & & & & & яндш ио & & & \\
\hline & $\|^{\circ}$ & & & & & & & kut & & & & & & & & & & & & \\
\hline
\end{tabular}


Note: The calculation bases on the calculation method shown in S7. For the calculation worldwide and Germany, starting point are the put-on-market devices (Gartner 2015; Statista 2015a, 2015b; Gartner 2016; Western Digital 2016; Jon Peddie Research 2016; IDC 2016) and (Cemix 2013). Data for collection of end-of-life in Germany bases on (stiftung elektro-altgeräte register 2015). All further calculations use data from disassembly trials conducted explicitly for this study, for other studies on the topic of strategically important metals (Ueberschaar et al. 2016) or generally within the work packages of the UPgrade project (Rotter et al. 2016).

Section S13 Selectivity for silver and gold vs. tantalum related to a removal of tantalum capacitors
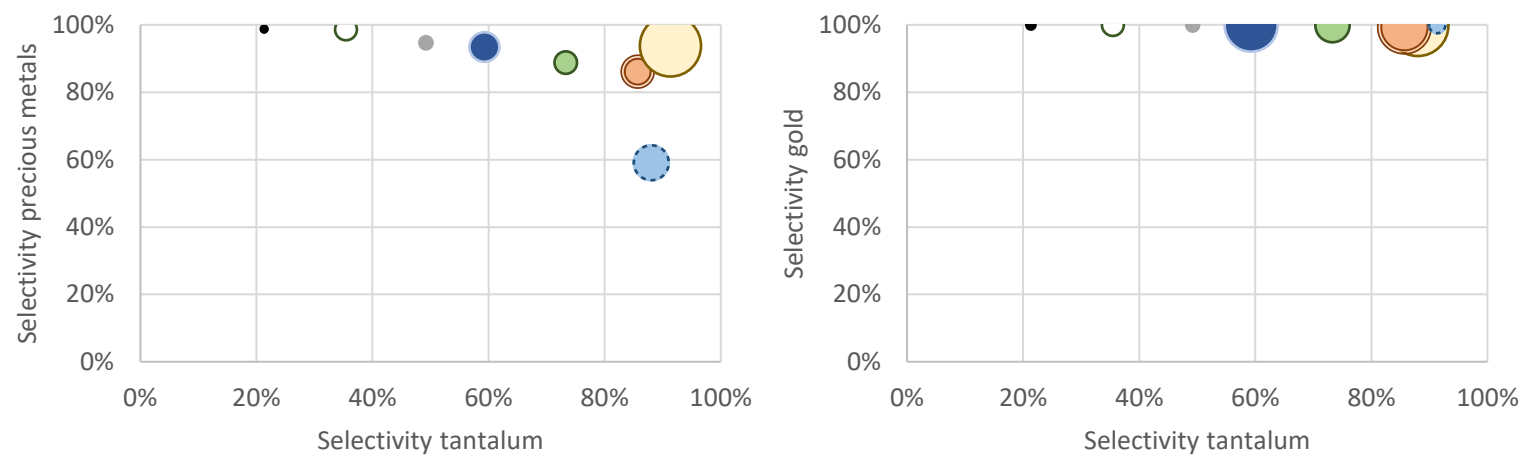

Desktop PC OTablets OMobile Phones OServer

- Hard Disk Drive Notebooks OSmartphones OTFT Monitor 
Section S14: Tantalum flows and distribution from PCB residues after VIC removal put-on-market and collected in Germany and worldwide in 2013

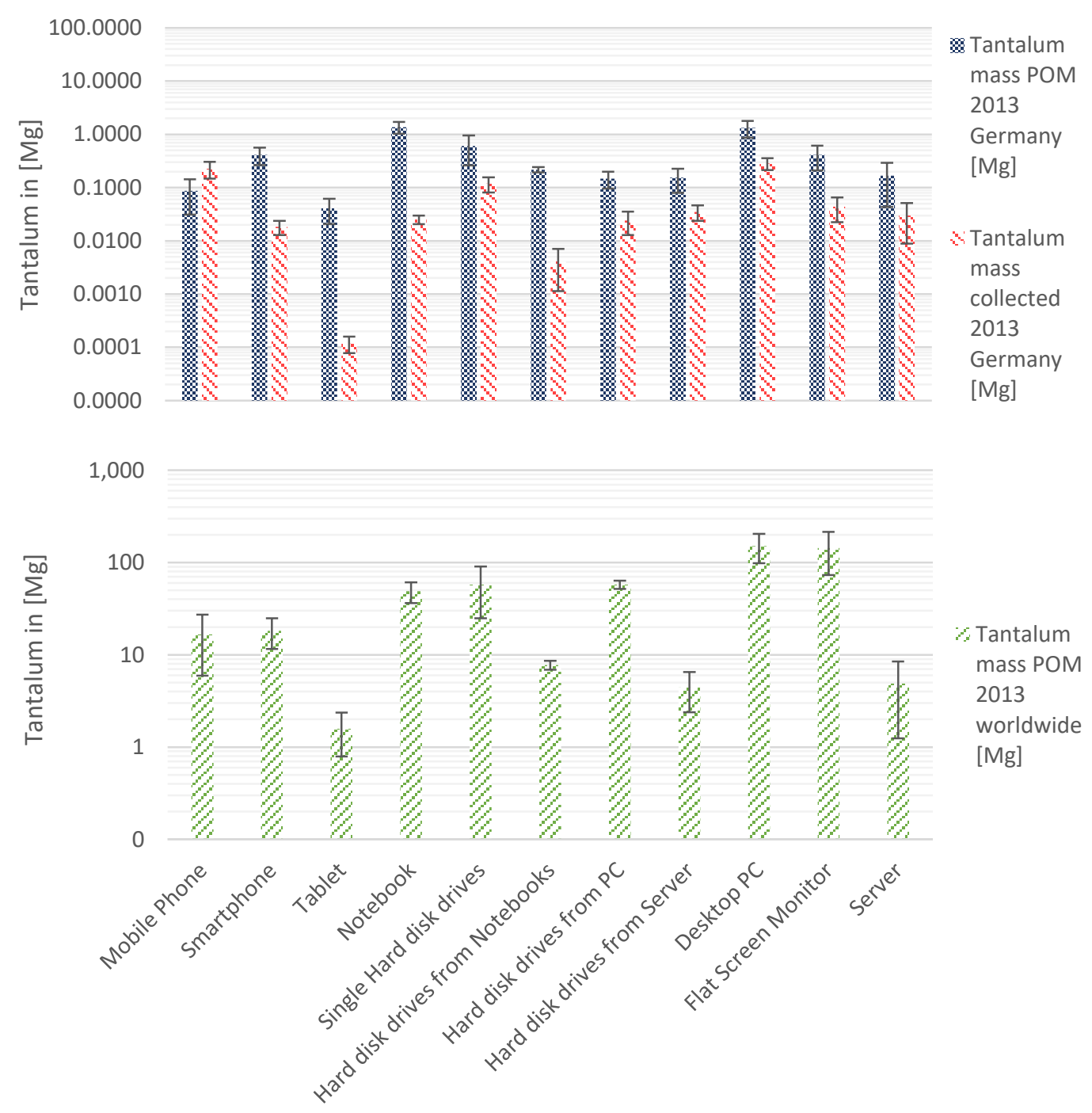

Figure S14-1: Tantalum from printed circuit boards (PCB) [with removed visually identifiable tantalum capacitors (VIC)] puton-market and collected in Germany and worldwide in 2013 
P-O-M Germany 2013

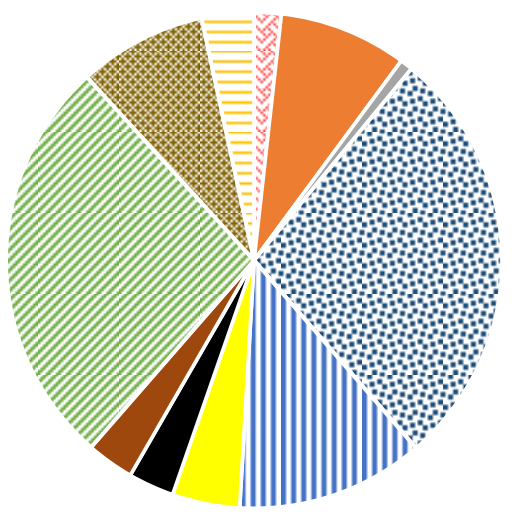

P-O-M worldwide 2013

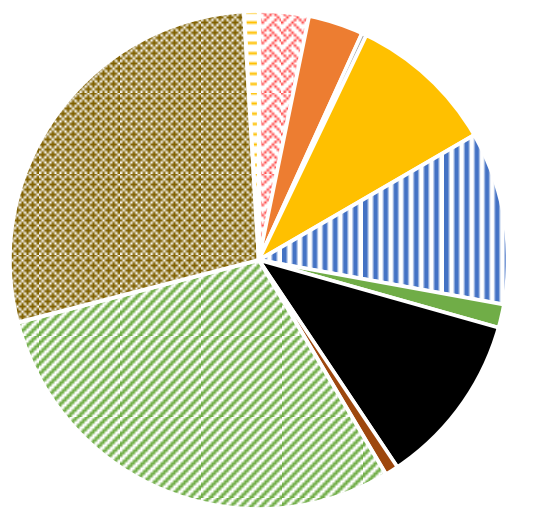

With WEEE collected Germany 2013

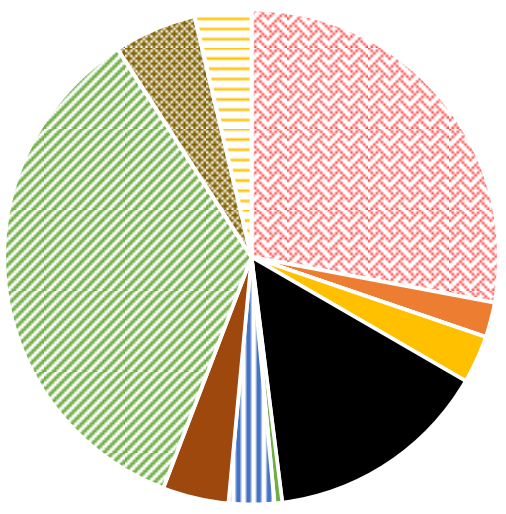

Mobile Phone
Smartphone
Tablet
Hard disk drives from PC
Wotebook
|||||| Single Hard disk drives
$\begin{aligned} & \text { Hard disk drives from } \\ & \text { Notebooks }\end{aligned}$

Figure S14-2: Distribution of tantalum flows through printed circuit boards (PCB) [with removed visually identifiable tantalum capacitors (VIC)] in EEE put-on-market and WEEE collected for recycling purposes 
Section S15: Tantalum flows and distribution from PCB with VIC puton-market and collected in Germany and worldwide in 2013
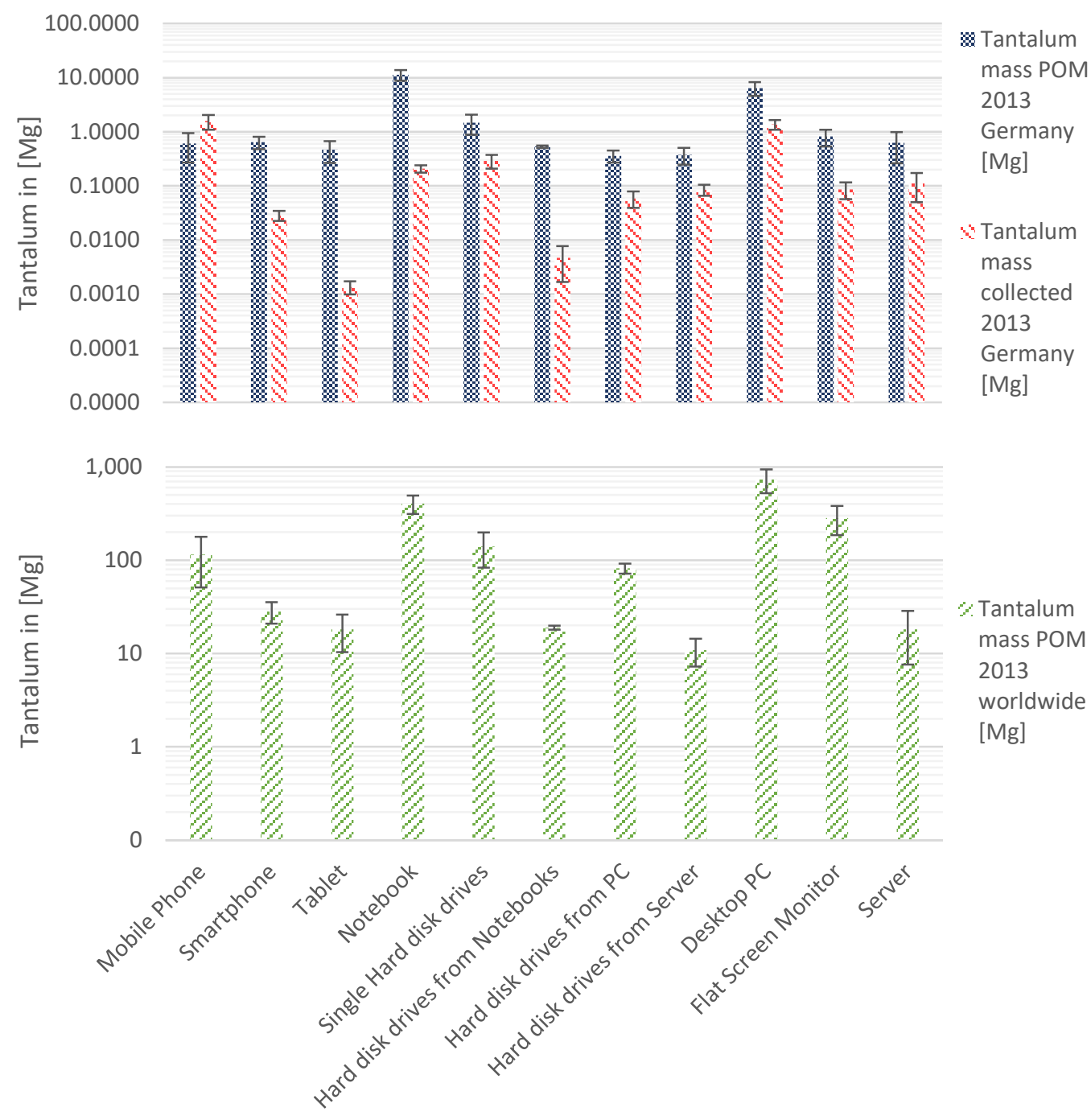

Figure S15-1: Tantalum from printed circuit boards (PCB) including visually identifiable tantalum capacitors (VIC) put-onmarket and collected in Germany and worldwide in 2013 
P-O-M Germany 2013

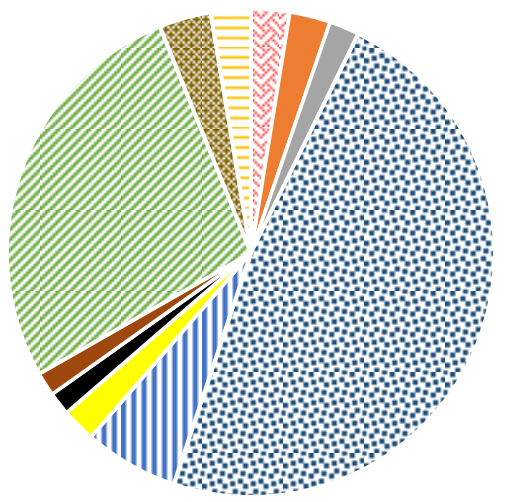

With WEEE collected Germany 2013

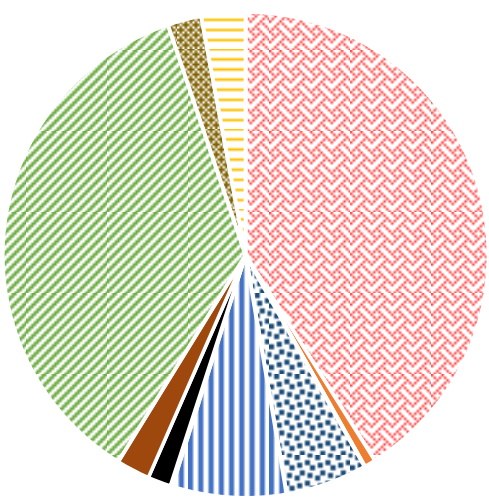

P-O-M worldwide 2013

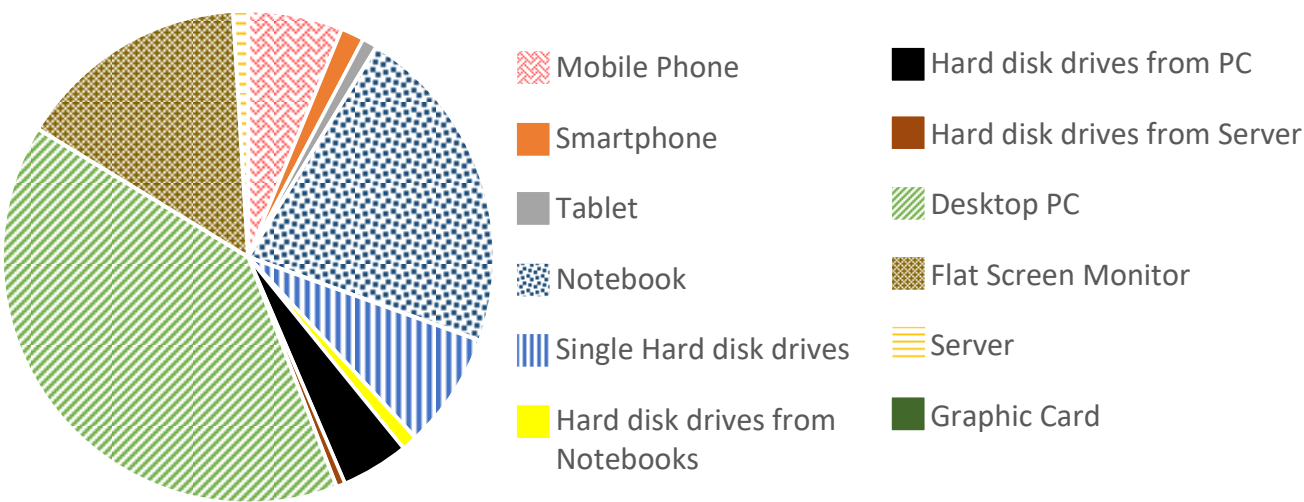

Figure S15-2: Distribution of tantalum flows through printed circuit boards (PCB) including visually identifiable tantalum capacitors (VIC) in EEE put-on-market and WEEE collected for recycling purposes 


\section{Section S16: Comparison of tantalum contribution from tantalum capacitors and PCB residues}

Figure S16 shows the tantalum flows put on market (POM) and collected coming from printed circuit boards (PCB) and visually identifiable tantalum capacitors (VIC).

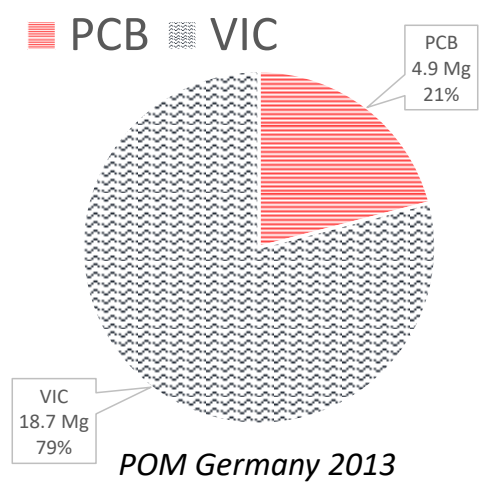

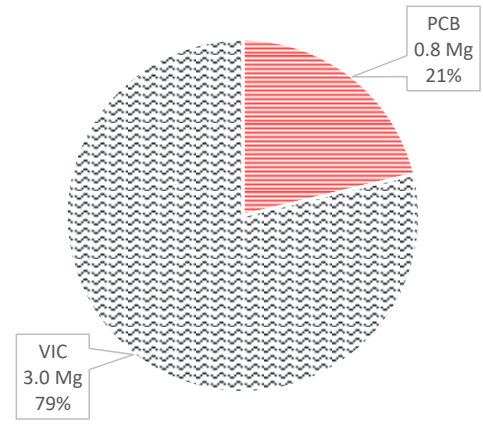

Collection Germany 2013

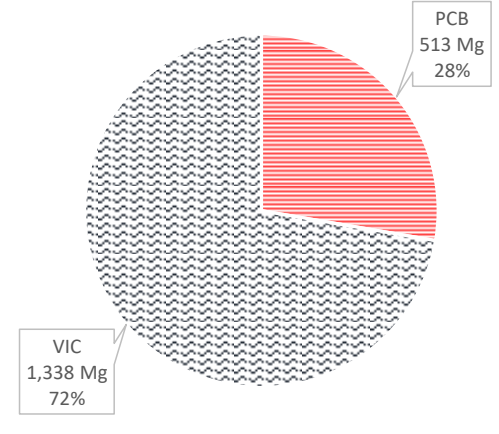

POM worldwide 2013

Figure S16: Share of printed circuit board (PCB) residues and visually identifiable tantalum capacitors (VIC) on the total tantalum flows put on market (POM) and collection in Germany and POM worldwide in 2013 


\section{References}

Baldé, K., C.P. Balde, R. Kuehr, K. Blumenthal, S. Fondeur Gill, M. Kern, P. Micheli, E. Magpantay, and J. Huisman. 2015. E-waste statistics - Guidelines on classification, reporting and indicators. Bonn: ESCAP, ESCWA, ITU, OECD, UNCTAD, UNECA, EUROSTAT, UNEP/SBC, UNU 3.

Buckingham, D.A., L.D. Cunningham, M.J. Magyar, and J.F. Papp. 2014. Tantalum Statistics.

Cemix. 2013. Consumer Electronics Marktindex Deutschland ( CEMIX) 2013. Cemix.

Chancerel, P., V.S. Rotter, M. Ueberschaar, M. Marwede, N.F. Nissen, and K.-D. Lang. 2013. Data availability and the need for research to localize, quantify and recycle critical metals in information technology, telecommunication and consumer equipment. Waste Management \& Research 31(10 Suppl): 3-16. http://wmr.sagepub.com/cgi/doi/10.1177/0734242X13499814. Accessed October 11, 2013.

Gartner. 2015. Absatz von Mobiltelefonen weltweit bis 2014. http://de.statista.com/statistik/daten/studie/192704/umfrage/absatz-von-mobiltelefonenweltweit-seit-2005/.

Gartner. 2016. Absatz von Servern weltweit vom 4. Quartal 2008 bis zum 1. Quartal 2016 nach Hersteller (in 1.000 Einheiten).

http://de.statista.com/statistik/daten/studie/154032/umfrage/auslieferungen-im-servermarktnach-herstellern-weltweit/.

IDC. 2016. Absatz von PC-Monitoren weltweit vom 1. Quartal 2012 bis zum 1. Quartal 2016 (in Millionen Stück). http://de.statista.com/statistik/daten/studie/274406/umfrage/absatz-von-pcmonitoren-weltweit-nach-quartalen/.

infoMine. 2016. 5 Year Tantalum Prices and Price Charts Tantalum Price Charts in Different Time Ranges. http://www.infomine.com/investment/metal-prices/tantalite-ore/5-year/. Accessed March 7, 2016.

Jon Peddie Research. 2016. Absatz von Grafikkarten weltweit in den Jahren 2009 bis 2015 (in Millionen Stück). http://de.statista.com/statistik/daten/studie/197684/umfrage/absatz-vongrafikkarten-weltweit-seit-2009/.

Rotter, V.S., M. Ueberschaar, G. Walter, S. Flamme, P. Chancerel, and Marwe. 2016. Final report UPgrade. Technische Universität Berlin, Institute of Environmental Technology, Chair of Circular Economy and Recycling Technology.

Schwela, U. 2010. The state of tantalum mining. Mining Journal.

Spitczok von Brisinski, L., D. Goldmann, and F. Endres. 2014. Recovery of Metals from Tantalum Capacitors with Ionic Liquids. Chemie Ingenieur Technik 86(1-2): 196-199. http://doi.wiley.com/10.1002/cite.201300059.

Statista. 2015a. Prognose zum Absatz von Tablets, Laptops und Desktop-PCs weltweit von 20102015. Statista.

Statista. 2015b. Absatz von LCD-Fernsehgeräten weltweit von 2007 bis 2015. Statista.

Stiftung elektro-altgeräte register. 2015. Rücknahmemengen je Sammelgruppe. https://www.stiftungear.de/service_und_aktuelles/kennzahlen/ruecknahmemengen_je_sammelgruppe. Accessed January 12, 2015.

stiftung elektro-altgeräte register. 2015. Jahres-Statistik-Meldung 2006-2014. 
Tantalum-Niobium International Study Center. 2011. TIC. In Bulletin N²145, 1-8.

Tantalum-Niobium International Study Center. 2013a. TIC. In Bulletin N 153.

Tantalum-Niobium International Study Center. 2013b. TIC. In Bulletin Nº 156.

Tantalum-Niobium International Study Center. 2016. TIC. In Bulletin N²164, 1-31.

Ueberschaar, M., V.S. Rotter, J. Geiping, S. Flamme, and M. Zamzow. 2016. Assessment of element specific recycling efficiency in WEEE pre-processing. To Be Sumitted in Resources, Conservation and Recycling.

USGS. 2016a. Tantalum facts 2011-2015.

http://minerals.usgs.gov/minerals/pubs/commodity/niobium/mcs-2016-tanta.pdf.

USGS. 2016b. Tantalum Worksheet Notes. http://minerals.usgs.gov/minerals/pubs/historicalstatistics/ds140-tanta.xlsx.

Western Digital. 2016. Absatz von Festplattenlaufwerken (HDD) weltweit vom 1. Quartal 2008 bis zum 1. Quartal 2016 (in Millionen Stück).

http://de.statista.com/statistik/daten/studie/200551/umfrage/absatz-von-

festplattenlaufwerken-weltweit/. 